\title{
The Effectiveness and Risks of Long-Term Opioid Treatment of Chronic Pain
}

\section{Executive Summary}

\section{Introduction}

\section{Background}

Chronic pain, often defined as pain lasting longer than 3 months or past the time of normal tissue healing, ${ }^{1}$ is extremely common. According to a recent Institute of Medicine report, up to one-third of U.S. adults report chronic pain. ${ }^{2}$ Chronic pain is a major cause of decreased quality of life and disability and is often refractory to treatment. ${ }^{3,4}$ There has been a dramatic increase over the past 10 to 20 years in the prescription of opioid medications for chronic pain, ${ }^{5-7}$ despite limited evidence showing long-term beneficial effects. ${ }^{8,9}$ In addition, accumulating evidence indicates that prescription opioids may be associated with important harms, including accidental overdose, abuse, addiction, diversion, and accidents involving injuries (such as falls and motor vehicle accidents). ${ }^{10-20}$ Perhaps of most concern is the dramatic increase in overdose deaths associated with opioids. In 2011, there were 16,917 fatal overdoses involving prescription opioids..$^{21}$ Prescription opioid misuse and abuse resulted in almost 660,000 emergency department visits in 2010, over twice as many as in $2004 .{ }^{13}$ Substance abuse treatment admissions for opiates other than heroin increased more than six-fold from 1999 to $2009 .{ }^{12}$ Opioids are also associated with adverse effects such as constipation, nausea, and sedation..$^{22}$ Finally, data indicate potential associations between long-term opioid therapy and other harms, such as adverse endocrinological effects and hyperalgesia..$^{23-25}$

\section{Evidence-based Practice Program}

The Agency for Healthcare Research and Quality (AHRQ), through its Evidencebased Practice Centers (EPCs), sponsors the development of evidence reports and technology assessments to assist publicand private-sector organizations in their efforts to improve the quality of health care in the United States. The reports and assessments provide organizations with comprehensive, science-based information on common, costly medical conditions and new health care technologies. The EPCs systematically review the relevant scientific literature on topics assigned to them by AHRQ and conduct additional analyses when appropriate prior to developing their reports and assessments.

AHRQ expects that the EPC evidence reports and technology assessments will inform individual health plans, providers, and purchasers as well as the health care system as a whole by providing important information to help improve health care quality.

The full report and this summary are available at www.effectivehealthcare.ahrq. gov/reports/final.cfm.

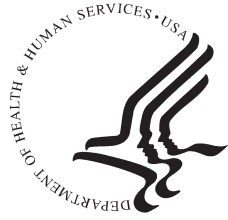


These data underscore the complexity of clinical decisionmaking around long-term opioid therapy, which requires individualized assessments of the balance between benefits and harms; appropriate opioid selection, dose initiation, and titration strategies; integration of risk assessment and mitigation strategies; and consideration of the use of alternative, nonopioid therapies. ${ }^{9}$ Risk mitigation strategies that have been suggested for patients prescribed long-term opioids include use of opioid medication agreements, application of dose thresholds that warrant increased caution, regular clinical followup and monitoring, urine drug screens, use of abuse- deterrent opioid formulations, and use of data from prescription drug monitoring programs. ${ }^{9}$

Understanding benefits and harms of long-term opioid therapy for chronic pain is a challenge because effects may vary depending on patient characteristics (e.g., age, sex, pain condition, psychosocial factors, comorbidities), opioid characteristics (e.g., specific opioid, short- versus long-acting opioid, mode of administration, dose), dosing strategies (e.g., round-the-clock versus as-needed dosing, application of dose thresholds), concomitant therapies (e.g., use of benzodiazepines or other drugs that may interact with opioids), and characteristics of the clinical setting. Other challenges in interpreting the literature include potential limitations in generalizability due to study design and other methodological shortcomings (e.g., duration of followup, exclusion of patients at higher risk for harms, under-representation of certain

sociodemographic groups, and high dropout rates), and gaps in research on important scientific questions. ${ }^{26}$ Although guidelines on use of opioids for chronic pain are available, most recommendations are based on weak or limited evidence. ${ }^{9,27}$ The increase in use of long-term opioid therapy for chronic pain, new information concerning harms associated with long-term opioid therapy, continued wide variations in practice related to long-term opioid therapy, and the availability of new evidence underscore the need for a current systematic review in this area.

The purpose of this report is to systematically review the current evidence on long-term opioid therapy for chronic pain, which will be used by the National Institutes of Health (NIH) to inform a Pathways to Prevention Workshop on the role of opioids in the treatment of chronic pain. Although guidelines have been published from the American Pain Society (APS)/American Academy of Pain Medicine, ${ }^{9}$ the Veterans Affairs (VA)/Department of Defense, ${ }^{28}$ and other groups, the availability of new evidence warrants a new systematic review that could be used to inform updated or new guidelines, guide quality improvement efforts, and define and update priorities for further research in this area. ${ }^{26}$ This review updates a prior systematic review on opioid therapy for chronic pain funded by the APS. ${ }^{29}$ Differences between this review and the 2009 APS review are that it focuses specifically on benefits and harms associated with long-term use of opioid therapy and evaluates an additional Key Question on dose escalation versus maintenance of doses in patients on long-term opioid therapy, additional outcomes (e.g., cardiovascular events, infection, and psychological outcomes), and additional risk mitigation strategies (e.g., abuse-deterrent formulations and use of data from prescription drug monitoring programs).

\section{Scope of Review and Key Questions}

The Key Questions and analytic framework (Figure A) used to guide this report are shown below. The analytic framework shows the target populations, interventions, and outcomes that we examined.

\section{Key Question 1. Effectiveness and Comparative Effectiveness}

a. In patients with chronic pain, what is the effectiveness of long-term opioid therapy versus placebo or no opioid therapy for long-term ( $>1$ year) outcomes related to pain, function, and quality of life?

b. How does effectiveness vary depending on: (1) the specific type or cause of pain (e.g., neuropathic, musculoskeletal [including low back pain], fibromyalgia, sickle cell disease, inflammatory pain, and headache disorders); (2) patient demographics (e.g., age, race, ethnicity, gender); (3) patient comorbidities (including past or current alcohol or substance use disorders, mental health disorders, medical comorbidities and high risk for addiction)?

c. In patients with chronic pain, what is the comparative effectiveness of opioids versus nonopioid therapies (pharmacological or nonpharmacological) on outcomes related to pain, function, and quality of life?

d. In patients with chronic pain, what is the comparative effectiveness of opioids plus nonopioid interventions (pharmacological or nonpharmacological) versus opioids or nonopioid interventions alone on outcomes related to pain, function, quality of life, and doses of opioids used?

\section{Key Question 2. Harms and Adverse Events}

a. In patients with chronic pain, what are the risks of opioids versus placebo or no opioid on: (1) opioid abuse, addiction, and related outcomes; (2) overdose; and (3) other harms, including gastrointestinal-related harms, falls, fractures, motor vehicle accidents, endocrinological harms, infections, cardiovascular 
events, cognitive harms, and psychological harms (e.g., depression)?

b. How do harms vary depending on: (1) the specific type or cause of pain (e.g., neuropathic, musculoskeletal [including back pain], fibromyalgia, sickle cell disease, inflammatory pain, headache disorders); (2) patient demographics; (3) patient comorbidities (including past or current substance use disorder or at high risk for addiction); (4) the dose of opioids used?

\section{Key Question 3. Dosing Strategies}

a. In patients with chronic pain, what is the comparative effectiveness of different methods for initiating and titrating opioids for outcomes related to pain, function, and quality of life; risk of overdose, addiction, abuse, or misuse; and doses of opioids used?

b. In patients with chronic pain, what is the comparative effectiveness of short- versus long- acting opioids on outcomes related to pain, function, and quality of life; risk of overdose, addiction, abuse, or misuse; and doses of opioids used?

c. In patients with chronic pain, what is the comparative effectiveness of different long- acting opioids on outcomes related to pain, function, and quality of life; and risk of overdose, addiction, abuse, or misuse?

d. In patients with chronic pain, what is the comparative effectiveness of short- plus long- acting opioids versus long-acting opioids alone on outcomes related to pain, function, and quality of life; risk of overdose, addiction, abuse, or misuse; and doses of opioids used?

e. In patients with chronic pain, what is the comparative effectiveness of scheduled, continuous versus as-needed dosing of opioids on outcomes related to pain, function, and quality of life; risk of overdose, addiction, abuse, or misuse; and doses of opioids used?

f. In patients with chronic pain on long-term opioid therapy, what is the comparative effectiveness of dose escalation versus dose maintenance or use of dose thresholds on outcomes related to pain, function, and quality of life?

g. In patients on long-term opioid therapy, what is the comparative effectiveness of opioid rotation versus maintenance of current opioid therapy on outcomes related to pain, function, and quality of life; and doses of opioids used?

h. In patients on long-term opioid therapy, what is the comparative effectiveness of different strategies for treating acute exacerbations of chronic pain on outcomes related to pain, function, and quality of life? i. In patients on long-term opioid therapy, what are the effects of decreasing opioid doses or of tapering off opioids versus continuation of opioids on outcomes related to pain, function, quality of life, and withdrawal?

j. In patients on long-term opioid therapy, what is the comparative effectiveness of different tapering protocols and strategies on measures related to pain, function, quality of life, withdrawal symptoms, and likelihood of opioid cessation?

\section{Key Question 4. Risk Assessment and Risk Mitigation Strategies}

a. In patients with chronic pain being considered for longterm opioid therapy, what is the accuracy of instruments for predicting risk of opioid overdose, addiction, abuse, or misuse?

b. In patients with chronic pain, what is the effectiveness of use of risk prediction instruments on outcomes related to overdose, addiction, abuse, or misuse?

c. In patients with chronic pain prescribed long-term opioid therapy, what is the effectiveness of risk mitigation strategies, including (1) opioid management plans, (2) patient education, (3) urine drug screening, (4) use of prescription drug monitoring program data, (5) use of monitoring instruments, (6) more frequent monitoring intervals, (7) pill counts, and (8) use of abuse-deterrent formulations on outcomes related to overdose, addiction, abuse, or misuse?

d. What is the comparative effectiveness of treatment strategies for managing patients with addiction to prescription opioids on outcomes related to overdose, abuse, misuse, pain, function, and quality of life?

\section{Methods}

The methods for this Comparative Effectiveness Review (CER) follow the methods suggested in the Agency for Healthcare Research and Quality (AHRQ) Methods Guide for Effectiveness and Comparative Effectiveness Reviews. ${ }^{30}$ All methods were determined a priori.

\section{Topic Refinement and Review Protocol}

This topic was selected for review based on a nomination from NIH. The initial Key Questions for this CER were developed with input from an NIH working group. The Key Questions and scope were further developed with input from a Technical Expert Panel (TEP) convened for this report. The TEP provided high-level content and methodological guidance to the review process and consisted of experts in health services research, internal medicine, psychology, pain medicine, pharmacology, 


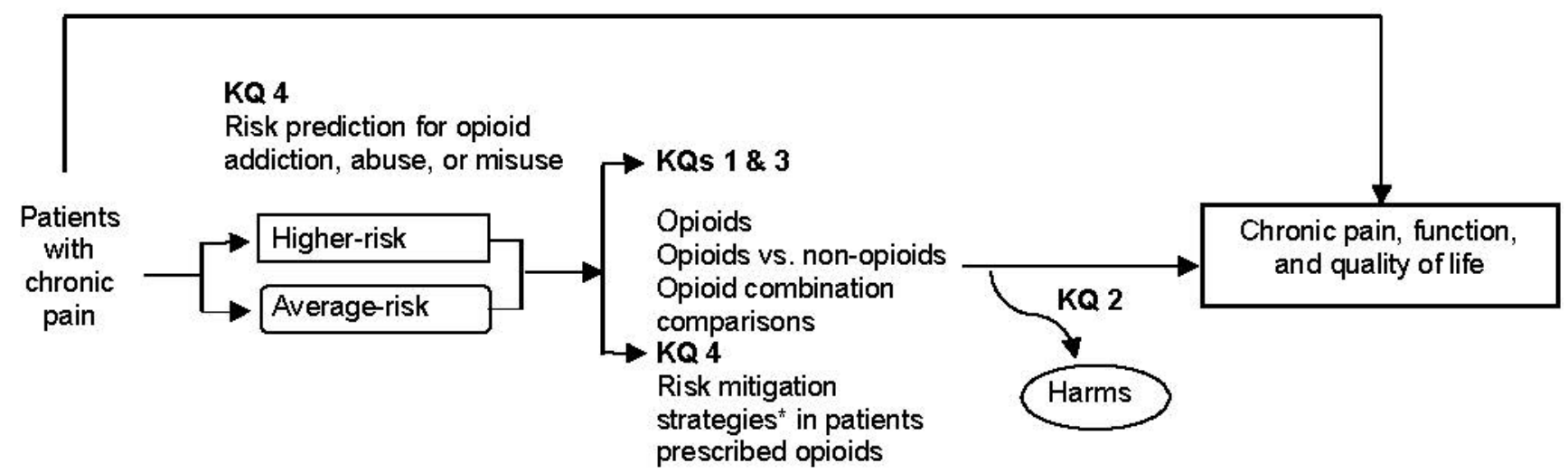

KQ, Key Question.

*Including opioid management plans, patient education, urine drug screening, use of prescription drug monitoring program data, use of monitoring instruments, more frequent monitoring intervals, pill counts, and use of abuse-deterrent formulations.

neurology, occupational medicine, pediatrics, and epidemiology. TEP members disclosed all financial or other conflicts of interest prior to participation. The AHRQ Task Order Officer and the investigators reviewed the disclosures and determined that the TEP members had no conflicts of interest that precluded participation.

The protocol for this CER was developed prior to initiation of the review, and was posted on the AHRQ Web site on December 19, 2013 at: http://effectivehealthcare.ahrq.gov/ ehc/products/557/1837/chronic-pain-opioid-treatmentprotocol-131219.pdf. The protocol was also registered in the PROSPERO international database of prospectively registered systematic reviews. ${ }^{31}$

\section{Literature Search Strategy}

A research librarian conducted searches in Ovid MEDLINE, the Cochrane Central Register of Controlled Trials, the Cochrane Database of Systematic Reviews, PsychINFO, and CINAHL from 2008 to August 2014 (see Appendix A in the full report for full search strategies). We restricted search start dates to January 2008 because the searches in the prior APS review, which we used to identify potentially relevant studies, went through October 2008. ${ }^{29}$ For outcomes (cardiovascular, infections, and psychological harms) and interventions (abuse-deterrent formulations, and use of prescription monitoring program data) not addressed in the APS review, we searched the same databases and did not apply any search date start restrictions.
We also hand-searched the reference lists of relevant studies and searched for unpublished studies in ClinicalTrials.gov. Scientific information packets (SIPs) with relevant published and unpublished studies were requested from 19 current application holders from the U.S. Food and Drug Administration (FDA) Risk Evaluation and Mitigation Strategy (REMS) Extended-Release and LongActing (ER/LA) Opioid Analgesics List. ${ }^{32}$ We received five SIP submissions.

\section{Study Selection}

We developed criteria for inclusion and exclusion of articles based on the Key Questions and the populations, interventions, comparators, outcomes, timing, and setting (PICOTS) approach (Appendix B in the full report). Articles were selected for full-text review if they were about long-term opioid therapy for chronic pain, were relevant to a Key Question, and met the predefined inclusion criteria as shown below. We excluded studies published only as conference abstracts, restricted inclusion to English-language articles, and excluded studies of nonhuman subjects. Studies had to report original data to be included.

Each abstract was independently reviewed for potential inclusion and full-text review by two investigators. Two investigators independently reviewed all full-text articles for final inclusion. Discrepancies were resolved through discussion and consensus. A list of the included articles is available in Appendix C; excluded articles are shown 
Appendix D with primary reasons for exclusion (see full report).

We selected studies of adults (age $>18$ years) with chronic pain (defined as pain lasting $>3$ months) being considered for long-term opioid therapy (Key Questions 4a and 4b) or prescribed long-term opioid therapy (all other Key Questions). We defined long-term opioid therapy as use of opioids on most days for $>3$ months; this threshold was selected to differentiate ongoing opioid therapy (as often used for chronic pain) from short-term therapy. We included studies that did not explicitly report the duration of pain if the average duration of opioid therapy was $>3$ months. We included studies that did not explicitly report the duration of opioid therapy if patients were prescribed long-acting opioids, as these are not typically prescribed for short-term use. We included studies with patients with chronic pain related to current or previously treated cancer, but excluded studies with patients with pain at end of life (e.g., patients with cancer in hospice care). We excluded studies with patients with acute pain, pregnant or breastfeeding women, and patients treated with opioids for addiction.

We included studies of patients prescribed any long- or short-acting opioid used as long-term therapy, either alone or in combination with another agent (Key Question 1d). We included tapentadol, a dual mechanism medication with strong opioid mu-receptor affinity, but excluded tramadol, which is also a dual mechanism medication but with weak opioid mu-receptor affinity that has not been identified as a cause of unintentional prescription drug overdose deaths. ${ }^{33}$ We also excluded studies of parenteral opioids.

We included studies that compared long-term opioid therapy versus placebo, no therapy, or another drug or nondrug therapy; studies that evaluated different dose initiation, titration, or rotation strategies; studies of different methods for tapering or discontinuing opioids; studies on methods for treating acute exacerbations of pain in people with chronic pain; and studies on various risk mitigation strategies for reducing harms associated with opioids. Risk mitigation strategies included opioid management plans, patient education, urine drug screening, use of prescription drug monitoring program data, use of monitoring instruments, more frequent monitoring intervals, pill counts, and use of abuse-deterrent formulations. We also included studies that compared the predictive accuracy of risk prediction instruments in people with chronic pain prior to initiation of opioids for predicting outcomes related to future misuse, abuse, or addiction, and studies on the effects of risk prediction instruments on clinical outcomes.
Outcomes were pain (intensity, severity, bothersomeness), function (physical disability, activity limitations, activity interference, work function), quality of life (including depression), and doses of opioids used. Evaluated harms included overdose, opioid use disorder, addiction, abuse, and misuse, as well as other opioid-related harms (including gastrointestinal harms, fractures, falls, motor vehicle accidents, endocrinological harms, infections, cardiovascular events, cognitive harms, and psychological harms [e.g., depression]). We focused on outcomes reported after at least 1 year of opioid therapy, with the exception of outcomes related to overdose and injuries (fractures, falls, and motor vehicle accidents), studies on treatment of acute exacerbations of chronic pain, studies on dose initiation and titration, and studies on discontinuation of opioid therapy, for which we included studies of any duration.

For all Key Questions, we included randomized trials and controlled observational studies (cohort studies, cross-sectional studies, and case-control studies) that performed adjustment on potential confounders. We included uncontrolled observational studies of patients with chronic pain prescribed opioid therapy for at least 1 year that reported abuse, misuse, or addiction as a primary outcome and described predefined methods to assess these outcomes. Otherwise, we excluded uncontrolled observational studies, case series, and case reports. We reviewed systematic reviews for potentially relevant references.

\section{Data Extraction}

We extracted the following information from included studies into evidence tables using Excel spreadsheets: study design, year, setting, inclusion and exclusion criteria, population characteristics (including sex, age, race, pain condition, and duration of pain), sample size, duration of followup, attrition, intervention characteristics (including specific opioid and formulation, dose, and duration of therapy), results, and funding sources.

For studies on the predictive accuracy of risk prediction instruments, we attempted to create two-by-two tables from information provided (sample size, prevalence, sensitivity, and specificity) and compared calculated measures of diagnostic accuracy based on the two-by-two tables with reported results. We noted discrepancies between calculated and reported results when present. When reported, we also recorded the area under the receiver operating characteristic curve (AUROC). ${ }^{34,35}$

For studies of interventions, we calculated relative risks (RR) and associated 95 percent confidence intervals (CI) based on the information provided (sample sizes and 
incidence of outcomes of interest in each intervention group). We noted discrepancies between calculated and reported results when present.

Data extraction for each study was performed by two investigators. The first investigator extracted the data, and the second investigator independently reviewed the extracted data for accuracy and completeness.

\section{Assessing Methodological Risk of Bias of Individual Studies}

We assessed risk of bias (quality) for each study using predefined criteria. We used the term "quality" rather than the alternate term "risk of bias;" both refer to internal validity. Randomized trials were evaluated with criteria and methods developed by the Cochrane Back Review Group. ${ }^{36}$ Cohort studies, case-control studies, and cross-sectional studies were rated using criteria from the U.S. Preventive Services Task Force. ${ }^{37}$ Risk prediction instrument studies were rated using criteria from various sources. ${ }^{38-40}$ These criteria were applied in conjunction with the approach recommended in the chapter, Assessing the Risk of Bias of Individual Studies When Comparing Medical Interventions,${ }^{41}$ in the AHRQ Methods Guide. Studies of predictive accuracy of risk prediction instruments were assessed using an approach adapted from the AHRQ Methods Guide for Medical Test Reviews, ${ }^{38}$ which is based on methods developed by the Quality Assessment of Diagnostic Accuracy Studies (QUADAS) group. ${ }^{39} \mathrm{We}$ reassessed the quality of studies included in the prior APS review to ensure consistency in quality assessment. Two investigators independently assessed the quality of each study. Discrepancies were resolved through discussion and consensus.

Individual studies were rated as having "poor," "fair," or "good" quality. We rated the quality of each randomized trial based on the methods used for randomization, allocation concealment, and blinding; the similarity of compared groups at baseline; whether attrition was adequately reported and acceptable; similarity in use of cointerventions; compliance to allocated treatments; the use of intent-to-treat analysis; and avoidance of selective outcomes reporting. ${ }^{36,37}$

We rated the quality of each cohort study based on whether it enrolled a consecutive or random sample of patients meeting inclusion criteria; whether it evaluated comparable groups; whether rates of loss to followup were reported and acceptable; whether it used accurate methods for ascertaining exposures, potential confounders, and outcomes; and whether it performed adjustment for important potential confounders. ${ }^{37}$ For cross-sectional studies, we used criteria for cohort studies, but did not rate criteria related to loss to followup. For uncontrolled studies on risk of abuse or related outcomes, we evaluated whether it enrolled a consecutive or random sample, whether outcome assessors were blinded to patient characteristics, whether rates of loss to followup were reported (for longitudinal studies) and acceptable, and whether prespecified outcomes were assessed in all patients.

We rated the quality of each case-control study based on whether it enrolled a consecutive or random sample of cases meeting predefined criteria; whether controls were derived from the same population as cases; whether cases and controls were comparable on key prognostic factors; whether it used accurate methods to ascertain outcomes, exposures, and potential confounders; and whether it performed adjustment for important potential confounders. ${ }^{37}$

We rated the quality of each study on the predictive value of risk prediction instruments based on whether it evaluated a consecutive or random sample of patients meeting predefined criteria, whether the patient population evaluated in the study was adequately described, whether the screening instrument included appropriate criteria, and whether outcomes were assessed in all patients independent of the results of the risk assessment instrument using adequately described methods. ${ }^{38,39} \mathrm{We}$ also evaluated whether the study was to develop a risk prediction instrument or to validate a previously developed instrument. ${ }^{40}$

Studies rated "good quality" were considered to have the least risk of bias and their results are likely to be valid. Studies rated "fair quality" have some methodological shortcomings, but no flaw or combination of flaws judged likely to cause major bias. In some cases, the article did not report important information, making it difficult to assess its methods or potential limitations. The moderate risk of bias category is broad and studies with this rating vary in their strengths and weaknesses; the results of some studies assessed to have moderate risk of bias are likely to be valid, while others may be only possibly valid. Studies rated "poor quality" have significant flaws that may invalidate the results. They have a serious or "fatal" flaw or combination of flaws in design, analysis, or reporting; large amounts of missing information; or serious discrepancies in reporting. The results of these studies are at least as likely to reflect flaws in the study design as the differences between the compared interventions. We did not exclude studies rated as having high risk of bias a priori, but they were considered the least reliable when synthesizing the evidence, particularly when discrepancies between studies were present. 


\section{Assessing Research Applicability}

We recorded factors important for understanding the applicability of studies, such as whether the publication adequately described the study sample, the country in which the study was conducted, the characteristics of the patient sample (e.g., age, sex, race, pain condition, duration or severity of pain, medical comorbidities, and psychosocial factors), the characteristics of the interventions used (e.g., specific opioid, dose, mode of administration, or dosing strategy), the clinical setting (e.g., primary care or specialty setting), and the magnitude of effects on clinical outcomes. ${ }^{42}$ We also recorded the funding source and role of the sponsor. We did not assign a rating of applicability (such as high or low) because applicability may differ based on the user of the report.

\section{Evidence Synthesis and Rating the Body of Evidence}

We constructed evidence tables summarizing study characteristics, results, and quality ratings for all included studies. We summarized evidence for each Key Question qualitatively used a hierarchy-of-evidence approach, where the best evidence was the focus of our synthesis for each Key Question. In the evidence tables, we included relevant studies from the prior APS review as well as new studies meeting inclusion criteria. Results were organized by Key Question. We did not attempt meta-analyses because of the small number of studies available for each Key Question; variability in study designs, patient samples, interventions, and measures; and methodological shortcomings in the available studies.

We assessed the overall strength of evidence (SOE) for each Key Question and outcome using the approach described in the AHRQ Methods Guide. ${ }^{30}$ We synthesized the quality of the studies; the consistency of results within and between study designs; the directness of the evidence linking the intervention and health outcomes; and the precision of the estimate of effect (based on the number and size of studies and CIs for the estimates). We were not able to formally assess for publication bias due to small number of studies, methodological shortcomings, or differences across studies in designs, measured outcomes, and other factors.

Rather, as described above, we searched for unpublished studies through searches of clinical trials registries and regulatory documents and by soliciting SIPs.

The SOE was based on the overall quality of each body of evidence, based on the risk of bias (graded low, moderate, or high); the consistency of results across studies (graded consistent, inconsistent, or unable to determine when only one study was available); the directness of the evidence linking the intervention and health outcomes (graded direct or indirect); and the precision of the estimate of effect, based on the number and size of studies and CIs for the estimates (graded precise or imprecise). We did not grade supplemental domains for cohort studies evaluating intermediate and clinical outcomes because too few studies were available for these factors to impact the SOE grades.

We graded the SOE for each Key Question using the four key categories recommended in the AHRQ Methods Guide..$^{30} \mathrm{~A}$ "high" grade indicates high confidence that the evidence reflects the true effect and that further research is very unlikely to change our confidence in the estimate of effect. A "moderate" grade indicates moderate confidence that the evidence reflects the true effect and further research may change our confidence in the estimate of effect and may change the estimate. A "low" grade indicates low confidence that the evidence reflects the true effect and further research is likely to change the confidence in the estimate of effect and is likely to change the estimate. An "insufficient" grade indicates evidence either is unavailable or is too limited to permit any conclusion, due to the availability of only poor-quality studies, extreme inconsistency, or extreme imprecision.

\section{Peer Review and Public Commentary}

Experts in chronic pain and opioid therapy, as well as individuals representing important stakeholder groups, were invited to provide external peer review of this CER. The AHRQ Task Order Officer and a designated EPC Associate Editor also provided comments and editorial review. To obtain public comment, the draft report was posted on the AHRQ Web site for 4 weeks. A disposition of comments report detailing the authors' responses to the peer and public review comments will be made available after AHRQ posts the final CER on the public Web site.

\section{Results}

\section{Overview}

The search and selection of articles are summarized in the study flow diagram (Figure B). Database searches resulted in 4,209 potentially relevant articles. After dual review of abstracts and titles, 667 articles were selected for full-text review, and 39 studies (in 40 publications) were determined by dual review at the full-text level to meet inclusion criteria and were included in this review. Data extraction and quality assessment tables for all included studies per Key Question are available in Appendixes E and F in the full report. 
Figure B. Literature flow diagram

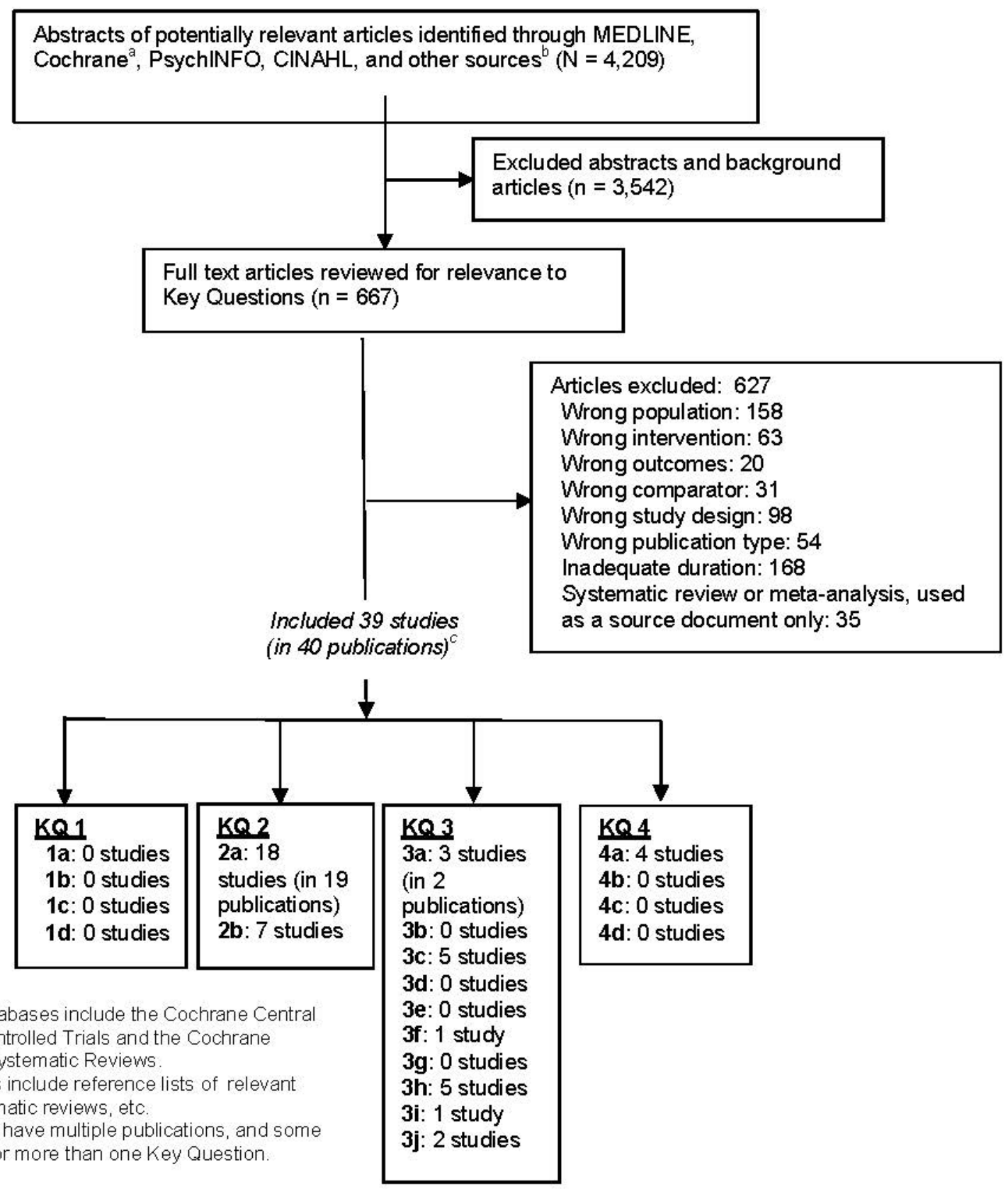

aCochrane databases include the Cochrane Central Register of Controlled Trials and the Cochrane Database of Systematic Reviews.

${ }^{b}$ Other sources include reference lists of relevant articles, systematic reviews, etc.

'Some studies have multiple publications, and some are included for more than one Key Question.

Articles excluded: 627

Wrong population: 158

Wrong intervention: 63

Wrong outcomes: 20

Wrong comparator: 31

Wrong study design: 98

Wrong publication type: 54

Inadequate duration: 168

Systematic review or meta-analysis, used as a source document only: 35 


\section{Key Question 1. Effectiveness and Comparative Effectiveness}

No study evaluated the effectiveness or comparative effectiveness of long-term opioid therapy versus placebo or no opioid therapy for long-term ( $>1$ year) outcomes related to pain, function, or quality of life in patients with chronic pain (SOE: insufficient).

\section{Key Question 2. Harms and Adverse Events}

In patients with chronic pain, 10 uncontrolled studies of patients on opioid therapy for at least 1 year that used predefined methods for ascertaining rates of abuse and related outcomes, rates of opioid abuse were 0.6 percent to 8 percent and rates of dependence were 3.1 percent to 26 percent in primary care settings, and rates of abuse were 14.4 percent, misuse 8 percent, and addiction 1.9 percent in pain clinic settings, but studies varied in methods used to define and ascertain outcomes. Rates of aberrant drugrelated behaviors (e.g., positive urine drug tests, medication agreement violations) ranged from 5.7 percent to 37.1 percent (SOE: insufficient). In controlled observational studies, opioids were associated with increased risk of abuse (one study), overdose (one study), fracture (two studies), myocardial infarction (two studies), and use of testosterone replacement or medications for erectile dysfunction (one study) versus no opioid use (strength of evidence: low). No study evaluated effects of opioids versus placebo or no opioid on gastrointestinal harms, motor vehicle accidents, infections, and psychological or cognitive harms.

In patients with chronic pain prescribed long-term opioid therapy, observational studies reported an association between higher doses of opioids and risk of abuse (one study), overdose (two studies), fracture (one study), myocardial infarction (one study), motor vehicle accidents (one study), and use or testosterone replacement or medications for erectile dysfunction (one study) (SOE: low). No study examined how harms vary depending on the specific type or cause of pain, patient demographics, or patient comorbidities (including past or current substance abuse disorder or being at high risk for addiction).

\section{Key Question 3. Dosing Strategies}

Three randomized, head-to-head trials of various longacting opioids found no differences in long-term outcomes related to pain or function (SOE: low). One retrospective cohort study conducted in a Veterans Affairs setting that used a propensity-adjusted analysis found methadone associated with lower mortality risk than sustained-release morphine (SOE: low). One randomized trial found no difference between more liberal dose escalation versus maintenance of current doses on outcomes related to pain, function, or withdrawal due to opioid use, but doses of opioids at the end of the trial in the two groups were similar (52 versus $40 \mathrm{mg}$ MED/day) (SOE: low). Five randomized trials found buccal or nasal fentanyl more effective than placebo or oral opioids for acute exacerbations of pain in patients with chronic pain, but focused on immediate (within 2 hours) outcomes (SOE: moderate). Studies on different methods for initiating and titrating opioids (three studies), decreasing doses or tapering off versus continuation (one study), and different tapering protocols and strategies (two studies), were limited in number, had methodological shortcomings, and showed no clear differences on outcomes related to pain and function (SOE: insufficient). No study examined effects of short- versus long-acting opioids, short- plus long-acting opioids versus long-acting opioids alone, scheduled, continuous versus as-needed dosing, or opioid rotation versus maintenance of current therapy in patients with chronic pain on long-term opioid therapy.

\section{Key Question 4. Risk Assessment and Risk Mitigation Strategies}

Four studies examined the accuracy of instruments for predicting risk of opioid overdose, addiction, abuse, or misuse in patients with chronic pain being considered for long-term opioid therapy. Three studies reported sensitivities for the Opioid Risk Tool that ranged from 0.20 to 0.99 (three studies) and specificities of 0.88 and 0.16 (two studies) (SOE: insufficient). Two studies found no clear differences between different risk assessment instruments in diagnostic accuracy. No study evaluated the effectiveness of the use of risk prediction instruments or other risk mitigation strategies, or the comparative effectiveness of treatment strategies for managing patients with a history of addiction on overdose, addiction, abuse, misuse, and related outcomes.

Key findings and SOE grades are summarized in the summary of evidence table (Table A).

The factors used to determine the overall SOE grades are available in Appendix $\mathrm{G}$ in the full report. 


\begin{tabular}{|c|c|c|}
\hline Key Question Outcome & $\begin{array}{l}\text { Strength of } \\
\text { Evidence } \\
\text { Grade }\end{array}$ & Conclusion \\
\hline \multicolumn{3}{|l|}{ 1. Effectiveness and comparative effectiveness } \\
\hline \multicolumn{3}{|l|}{$\begin{array}{l}\text { a. In patients with chronic pain, what is the } \\
\text { effectiveness of long-term opioid therapy versus } \\
\text { placebo or no opioid therapy for long-term ( }>1 \text { year) } \\
\text { outcomes related to pain, function, and quality of life? }\end{array}$} \\
\hline Pain, function, quality of life & Insufficient & $\begin{array}{l}\text { No study of opioid therapy versus placebo or no opioid } \\
\text { therapy evaluated long-term ( }>1 \text { year) outcomes related } \\
\text { to pain, function, or quality of life }\end{array}$ \\
\hline \multicolumn{3}{|l|}{$\begin{array}{l}\text { b. How does effectiveness vary depending on: (1) } \\
\text { the specific type or cause of pain (e.g., neuropathic, } \\
\text { musculoskeletal [including low back pain], } \\
\text { fibromyalgia, sickle cell disease, inflammatory pain, } \\
\text { and headache disorders); (2) patient demographics } \\
\text { (e.g., age, race, ethnicity, gender); (3) patient } \\
\text { comorbidities (including past or current alcohol or } \\
\text { substance use disorders, mental health disorders, } \\
\text { medical comorbidities and high risk for addiction)? }\end{array}$} \\
\hline Pain, function, quality of life & Insufficient & No studies \\
\hline \multicolumn{3}{|l|}{$\begin{array}{l}\text { c. In patients with chronic pain, what is the } \\
\text { comparative effectiveness of opioids versus nonopioid } \\
\text { therapies (pharmacological or nonpharmacological) on } \\
\text { outcomes related to pain, function, and quality of life? }\end{array}$} \\
\hline Pain, function, quality of life & Insufficient & No studies \\
\hline \multicolumn{3}{|l|}{$\begin{array}{l}\text { d. In patients with chronic pain, what is the } \\
\text { comparative effectiveness of opioids plus } \\
\text { nonopioid interventions (pharmacological or } \\
\text { nonpharmacological) versus opioids or nonopioid } \\
\text { interventions alone on outcomes related to pain, } \\
\text { function, quality of life, and doses of opioids used? }\end{array}$} \\
\hline Pain, function, quality of life & Insufficient & No Studies \\
\hline \multicolumn{3}{|l|}{ 2. Harms and adverse events } \\
\hline \multicolumn{3}{|l|}{$\begin{array}{l}\text { a. In patients with chronic pain, what are the risks of } \\
\text { opioids versus placebo or no opioid on: (1) opioid } \\
\text { abuse, addiction, and related outcomes; (2) overdose; } \\
\text { and (3) other harms, including gastrointestinal-related } \\
\text { harms, falls, fractures, motor vehicle accidents, } \\
\text { endocrinological harms, infections, cardiovascular } \\
\text { events, cognitive harms, and psychological harms } \\
\text { (e.g., depression)? }\end{array}$} \\
\hline Abuse, addiction & Low & $\begin{array}{l}\text { No randomized trial evaluated risk of opioid abuse, } \\
\text { addiction, and related outcomes in patients with chronic } \\
\text { pain prescribed opioid therapy. One retrospective cohort } \\
\text { study found prescribed long-term opioid use associated } \\
\text { with significantly increased risk of abuse or dependence } \\
\text { versus no opioid use. }\end{array}$ \\
\hline
\end{tabular}


Table A. Summary of evidence (continued)

\begin{tabular}{|c|c|c|}
\hline Key Question Outcome & $\begin{array}{l}\text { Strength of } \\
\text { Evidence } \\
\text { Grade }\end{array}$ & Conclusion \\
\hline Abuse, addiction & Insufficient & $\begin{array}{l}\text { In } 10 \text { uncontrolled studies, estimates of opioid abuse, } \\
\text { addiction, and related outcomes varied substantially even } \\
\text { after stratification by clinic setting }\end{array}$ \\
\hline Overdose & Low & $\begin{array}{l}\text { Current opioid use was associated with increased risk of } \\
\text { any overdose events (adjusted HR 5.2, 95\% CI 2.1 to 12) } \\
\text { and serious overdose events (adjusted HR 8.4, 95\% CI } \\
2.5 \text { to } 28 \text { ) versus current nonuse }\end{array}$ \\
\hline Fractures & Low & $\begin{array}{l}\text { Opioid use associated with increased risk of fracture in } \\
1 \text { cohort study (adjusted HR } 1.28,95 \% \text { CI } 0.99 \text { to } 1.64 \text { ) } \\
\text { and } 1 \text { case-control study (adjusted OR } 1.27,95 \% \text { CI } 1.21 \\
\text { to } 1.33 \text { ) }\end{array}$ \\
\hline Myocardial infarction & Low & $\begin{array}{l}\text { Current opioid use associated with increased risk of } \\
\text { myocardial infarction versus nonuse (adjusted OR } 1.28 \text {, } \\
95 \% \text { CI } 1.19 \text { to } 1.37 \text { and incidence rate ratio } 2.66,95 \% \\
\text { CI } 2.30 \text { to } 3.08 \text { ) } \\
\end{array}$ \\
\hline Endocrine & Low & $\begin{array}{l}\text { Long-term opioid use associated with increased risk } \\
\text { of use of medications for erectile dysfunction or } \\
\text { testosterone replacement versus nonuse (adjusted OR 1.5, } \\
95 \% \text { CI } 1.1 \text { to 1.9) }\end{array}$ \\
\hline $\begin{array}{l}\text { Gastrointestinal harms, motor vehicle accidents, } \\
\text { infections, psychological harms, cognitive harms }\end{array}$ & Insufficient & No studies \\
\hline $\begin{array}{l}\text { b. How do harms vary depending on: (1) the } \\
\text { specific type or cause of pain (e.g., neuropathic, } \\
\text { musculoskeletal [including back pain], fibromyalgia, } \\
\text { sickle cell disease, inflammatory pain, headache } \\
\text { disorders); (2) patient demographics; (3) patient } \\
\text { comorbidities (including past or current substance use } \\
\text { disorder or at high risk for addiction)? }\end{array}$ & & \\
\hline Various harms & Insufficient & No studies \\
\hline \multicolumn{3}{|l|}{$\begin{array}{l}\text { b. How do harms vary depending on the dose of } \\
\text { opioids used? }\end{array}$} \\
\hline Abuse, addiction & Low & $\begin{array}{l}\text { One retrospective cohort study found higher doses of } \\
\text { long-term opioid therapy associated with increased } \\
\text { risk of opioid abuse or dependence than lower doses. } \\
\text { Compared to no opioid prescription, the adjusted odds } \\
\text { ratios were } 15 \text { ( } 95 \text { percent CI } 10 \text { to } 21 \text { ) for } 1-36 \mathrm{MED} / \\
\text { day, } 29 \text { ( } 95 \text { percent CI } 20 \text { to } 41 \text { ) for } 36-120 \mathrm{MED} / \text { day, } \\
\text { and } 122 \text { ( } 95 \text { percent CI } 73 \text { to } 205 \text { ) for } \geq 120 \mathrm{MED/day.}\end{array}$ \\
\hline Overdose & Low & $\begin{array}{l}\text { Versus } 1 \text { to } 19 \mathrm{mg} \text { MED/day, } 1 \text { cohort study found an } \\
\text { adjusted HR for an overdose event of } 1.44 \text { ( } 95 \% \text { CI } 0.57 \\
\text { to } 3.62 \text { ) for } 20 \text { to } 49 \mathrm{mg} \text { MED/day that increased to } 11.18 \\
\text { ( } 95 \% \text { CI } 4.80 \text { to } 26.03) \text { at }>100 \mathrm{mg} \text { MED/day; } 1 \text { case- } \\
\text { control study found an adjusted OR for an opioid-related } \\
\text { death of } 1.32(95 \% \text { CI } 0.94 \text { to } 1.84) \text { for } 20 \text { to } 49 \mathrm{mg} \\
\text { MED/day that increased to } 2.88 \text { (95\% CI } 1.79 \text { to } 4.63) \text { at } \\
\geq 200 \mathrm{mg} \mathrm{MED/day}\end{array}$ \\
\hline
\end{tabular}


Table A. Summary of evidence (continued)

\begin{tabular}{|c|c|c|}
\hline Key Question Outcome & $\begin{array}{c}\text { Strength of } \\
\text { Evidence } \\
\text { Grade }\end{array}$ & Conclusion \\
\hline Fracture & Low & $\begin{array}{l}\text { Risk of fracture increased from an adjusted HR of } 1.20 \\
(95 \% \text { CI } 0.92 \text { to } 1.56) \text { at } 1 \text { to }<20 \mathrm{mg} \mathrm{MED/day} \mathrm{to} 2.00 \\
(95 \% \text { CI } 1.24 \text { to } 3.24) \text { at } \geq 50 \mathrm{mg} \mathrm{MED/day} \text {; the trend was } \\
\text { of borderline statistical significance }\end{array}$ \\
\hline Myocardial infarction & Low & $\begin{array}{l}\text { Relative to a cumulative dose of } 0 \text { to } 1350 \mathrm{mg} \text { MED over } \\
90 \text { days, the incidence rate ratio for myocardial infarction } \\
\text { for } 1350 \text { to }<2700 \mathrm{mg} \text { was } 1.21 \text { ( } 95 \% \text { CI } 1.02 \text { to } 1.45) \text {, } \\
\text { for } 2700 \text { to }<8100 \mathrm{mg} \text { was } 1.42(95 \% \text { CI } 1.21 \text { to } 1.67) \text {, } \\
\text { for } 8100 \text { to }<18,000 \mathrm{mg} \text { was } 1.89(95 \% \text { CI } 1.54 \text { to } 2.33 \text { ), } \\
\text { and for }>18,000 \mathrm{mg} \text { was } 1.73 \text { (95\% CI } 1.32 \text { to } 2.26)\end{array}$ \\
\hline Motor vehicle accidents & Low & $\begin{array}{l}\text { No association between opioid dose and risk of motor } \\
\text { vehicle accidents. }\end{array}$ \\
\hline Endocrine & Low & $\begin{array}{l}\text { Relative to } 0 \text { to }<20 \mathrm{mg} \mathrm{MED} / \text { day, the adjusted OR } \\
\text { for daily opioid dose of } \geq 120 \mathrm{mg} \mathrm{MED} / \text { day for use of } \\
\text { medications for erectile dysfunction or testosterone } \\
\text { replacement was } 1.6(95 \% \text { CI } 1.0 \text { to } 2.4)\end{array}$ \\
\hline 3. Dosing strategies & & \\
\hline \multicolumn{3}{|l|}{$\begin{array}{l}\text { a. In patients with chronic pain, what is the } \\
\text { comparative effectiveness of different methods for } \\
\text { initiating and titrating opioids for outcomes related to } \\
\text { pain, function, and quality of life; risks of overdose, } \\
\text { addiction, abuse, or misuse; and doses of opioids } \\
\text { used? }\end{array}$} \\
\hline Pain & Insufficient & $\begin{array}{l}\text { Evidence from three trials on effects of titration with } \\
\text { immediate-release versus sustained-release opioids } \\
\text { reported inconsistent results on outcomes related to pain } \\
\text { and are difficult to interpret due to additional differences } \\
\text { between treatment arms in dosing protocols (titrated vs. } \\
\text { fixed dosing) and doses of opioids used }\end{array}$ \\
\hline Function, quality of life, outcomes related to abuse & Insufficient & No studies \\
\hline \multicolumn{3}{|l|}{$\begin{array}{l}\text { b. In patients with chronic pain, what is the } \\
\text { comparative effectiveness of short- versus long- acting } \\
\text { opioids on outcomes related to pain, function, and } \\
\text { quality of life; risk of overdose, addiction, abuse, or } \\
\text { misuse; and doses of opioids used? }\end{array}$} \\
\hline $\begin{array}{r}\text { Pain, function, quality of life, outcomes } \\
\text { related to abuse }\end{array}$ & Insufficient & No studies \\
\hline \multicolumn{3}{|l|}{$\begin{array}{l}\text { c. In patients with chronic pain, what is the } \\
\text { comparative effectiveness of different long- acting } \\
\text { opioids on outcomes related to pain, function, and } \\
\text { quality of life; and risk of overdose, addiction, abuse, } \\
\text { or misuse? }\end{array}$} \\
\hline Pain and function & Low & No difference between various long-acting opioids \\
\hline
\end{tabular}


Table A. Summary of evidence (continued)

\begin{tabular}{|c|c|c|}
\hline Key Question Outcome & $\begin{array}{l}\text { Strength of } \\
\text { Evidence } \\
\text { Grade }\end{array}$ & Conclusion \\
\hline $\begin{array}{r}\text { Assessment of risk of overdose, addiction, } \\
\text { abuse, or misuse }\end{array}$ & Insufficient & $\begin{array}{l}\text { No studies were designed to assess risk of overdose, } \\
\text { addiction, abuse, or misuse }\end{array}$ \\
\hline Overdose (as indicated by all-cause mortality) & Low & $\begin{array}{l}\text { One cohort study found methadone to be associated with } \\
\text { lower all-cause mortality risk than sustained-release } \\
\text { morphine in a propensity adjusted analysis }\end{array}$ \\
\hline \multicolumn{3}{|l|}{ 3. Dosing strategies (continued) } \\
\hline Abuse and related outcomes & Insufficient & $\begin{array}{l}\text { Another cohort study found some differences between } \\
\text { long-acting opioids in rates of adverse outcomes related } \\
\text { to abuse, but outcomes were nonspecific for opioid- } \\
\text { related adverse events, precluding reliable conclusions }\end{array}$ \\
\hline \multicolumn{3}{|l|}{$\begin{array}{l}\text { d. In patients with chronic pain, what is the } \\
\text { comparative effectiveness of short- plus long- acting } \\
\text { opioids vs. long-acting opioids alone on outcomes } \\
\text { related to pain, function, and quality of life; risk of } \\
\text { overdose, addiction, abuse, or misuse; and doses of } \\
\text { opioids used? }\end{array}$} \\
\hline $\begin{array}{r}\text { Pain, function, quality of life, outcomes } \\
\text { related to abuse }\end{array}$ & Insufficient & No studies \\
\hline \multicolumn{3}{|l|}{$\begin{array}{l}\text { e. In patients with chronic pain, what is the } \\
\text { comparative effectiveness of scheduled, continuous } \\
\text { versus as-needed dosing of opioids on outcomes } \\
\text { related to pain, function, and quality of life; risk of } \\
\text { overdose, addiction, abuse, or misuse; and doses of } \\
\text { opioids used? }\end{array}$} \\
\hline $\begin{array}{r}\text { Pain, function, quality of life, outcomes } \\
\text { related to abuse }\end{array}$ & Insufficient & No studies \\
\hline \multicolumn{3}{|l|}{$\begin{array}{l}\text { f. In patients with chronic pain on long-term opioid } \\
\text { therapy, what is the comparative effectiveness of dose } \\
\text { escalation versus dose maintenance or use of dose } \\
\text { thresholds on outcomes related to pain, function, and } \\
\text { quality of life? }\end{array}$} \\
\hline Pain, function, withdrawal due to opioid misuse & Low & $\begin{array}{l}\text { No difference between more liberal dose escalation } \\
\text { versus maintenance of current doses in pain, function, or } \\
\text { risk of withdrawal due to opioid misuse, but there was } \\
\text { limited separation in opioid doses between groups ( } 52 \mathrm{vs} \text {. } \\
40 \mathrm{mg} \mathrm{MED/day} \mathrm{at} \mathrm{the} \mathrm{end} \mathrm{of} \mathrm{the} \mathrm{trial)}\end{array}$ \\
\hline $\begin{array}{l}\text { g. In patients on long-term opioid therapy, what is the } \\
\text { comparative effectiveness of opioid rotation versus } \\
\text { maintenance of current opioid therapy on outcomes } \\
\text { related to pain, function, and quality of life; and doses } \\
\text { of opioids used? }\end{array}$ & & \\
\hline
\end{tabular}


Table A. Summary of evidence (continued)

\begin{tabular}{|c|c|c|}
\hline Key Question Outcome & $\begin{array}{l}\text { Strength of } \\
\text { Evidence } \\
\text { Grade }\end{array}$ & Conclusion \\
\hline \multicolumn{3}{|l|}{ 3. Dosing strategies (continued) } \\
\hline $\begin{array}{r}\text { Pain, function, quality of life, outcomes } \\
\text { related to abuse }\end{array}$ & Insufficient & No studies \\
\hline \multicolumn{3}{|l|}{$\begin{array}{l}\text { h. In patients on long-term opioid therapy, what is } \\
\text { the comparative effectiveness of different strategies } \\
\text { for treating acute exacerbations of chronic pain on } \\
\text { outcomes related to pain, function, and quality of life? }\end{array}$} \\
\hline Pain & Moderate & $\begin{array}{l}\text { Two randomized trials found buccal fentanyl more } \\
\text { effective than placebo for treating acute exacerbations of } \\
\text { pain and three randomized trials found buccal fentanyl } \\
\text { or intranasal fentanyl more effective than oral opioids for } \\
\text { treating acute exacerbations of pain in patients on long- } \\
\text { term opioid therapy, based on outcomes measured up to } 2 \\
\text { hours after dosing Abuse and related outcomes }\end{array}$ \\
\hline Abuse and related outcomes & Insufficient & No studies \\
\hline \multicolumn{3}{|l|}{$\begin{array}{l}\text { i. In patients on long-term opioid therapy, what are } \\
\text { the effects of decreasing opioid doses or of tapering } \\
\text { off opioids versus continuation of opioids on } \\
\text { outcomes related to pain, function, quality of life, and } \\
\text { withdrawal? }\end{array}$} \\
\hline Pain, function & Insufficient & $\begin{array}{l}\text { Abrupt cessation of morphine was associated with } \\
\text { increased pain and decreased function compared to } \\
\text { continuation of morphine }\end{array}$ \\
\hline \multicolumn{3}{|l|}{$\begin{array}{l}\text { j. In patients on long-term opioid therapy, what is } \\
\text { the comparative effectiveness of different tapering } \\
\text { protocols and strategies on measures related to pain, } \\
\text { function, quality of life, withdrawal symptoms, and } \\
\text { likelihood of opioid cessation? }\end{array}$} \\
\hline Opioid abstinence & Insufficient & $\begin{array}{l}\text { No clear differences between different methods for } \\
\text { opioid discontinuation or tapering in likelihood of opioid } \\
\text { abstinence after } 3 \text { to } 6 \text { months }\end{array}$ \\
\hline \multicolumn{3}{|l|}{ 4. Risk assessment and risk mitigation strategies } \\
\hline \multicolumn{3}{|l|}{$\begin{array}{l}\text { a. In patients with chronic pain being considered } \\
\text { for long-term opioid therapy, what is the accuracy of } \\
\text { instruments for predicting risk of opioid overdose, } \\
\text { addiction, abuse, or misuse? }\end{array}$} \\
\hline Diagnostic accuracy: Opioid Risk Tool & Insufficient & $\begin{array}{l}\text { Based on a cutoff of }>4 \text {, three studies (one poor- quality, } \\
\text { two poor-quality) reported very inconsistent estimates of } \\
\text { diagnostic accuracy, precluding reliable conclusions }\end{array}$ \\
\hline $\begin{array}{r}\text { Diagnostic accuracy: Screening and Opioid } \\
\text { Assessment for Patients with Pain (SOAPP) version } 1\end{array}$ & Low & $\begin{array}{l}\text { Based on a cutoff score of }>8 \text {, sensitivity was } 0.68 \text { and } \\
\text { specificity of } 0.38 \text { in } 1 \text { study, for a PLR of } 1.11 \text { and NLR } \\
\text { of } 0.83 \text {. Based on a cutoff score of }>6 \text {, sensitivity was } \\
0.73 \text { in } 1 \text { study }\end{array}$ \\
\hline
\end{tabular}


Table A. Summary of evidence (continued)

\begin{tabular}{|c|c|c|}
\hline Key Question Outcome & $\begin{array}{l}\text { Strength of } \\
\text { Evidence } \\
\text { Grade }\end{array}$ & Conclusion \\
\hline \multicolumn{3}{|l|}{$\begin{array}{l}\text { 4. Risk assessment and risk mitigation strategies } \\
\text { (continued) }\end{array}$} \\
\hline \multicolumn{3}{|l|}{$\begin{array}{l}\text { b. In patients with chronic pain, what is the } \\
\text { effectiveness of use of risk prediction instruments on } \\
\text { outcomes related to overdose, addiction, abuse, or } \\
\text { misuse? }\end{array}$} \\
\hline Outcomes related to abuse & Insufficient & $\begin{array}{l}\text { No study evaluated the effectiveness of risk prediction } \\
\text { instruments for reducing outcomes related to overdose, } \\
\text { addiction, abuse, or misuse }\end{array}$ \\
\hline \multicolumn{3}{|l|}{$\begin{array}{l}\text { c. In patients with chronic pain prescribed long- } \\
\text { term opioid therapy, what is the effectiveness of risk } \\
\text { mitigation strategies, including 1) opioid management } \\
\text { plans, 2) patient education, 3) urine drug screening, } \\
\text { 4) use of prescription drug monitoring program data, } \\
\text { 5) use of monitoring instruments, 6) more frequent } \\
\text { monitoring intervals, 7) pill counts, and 8) use of } \\
\text { abuse-deterrent formulations on outcomes related to } \\
\text { overdose, addiction, abuse, or misuse? }\end{array}$} \\
\hline Outcomes related to abuse & Insufficient & No studies \\
\hline \multicolumn{3}{|l|}{$\begin{array}{l}\text { d. What is the comparative effectiveness of treatment } \\
\text { strategies for managing patients with addiction to } \\
\text { prescription opioids on outcomes related to overdose, } \\
\text { abuse, misuse, pain, function, and quality of life? }\end{array}$} \\
\hline Outcomes related to abuse & Insufficient & No studies \\
\hline
\end{tabular}

Abbreviations: $\mathrm{CI}=$ confidence interval, $\mathrm{HR}=$ hazard ratio, $\mathrm{MED}=$ morphine equivalent dose, $\mathrm{mg}=$ milligrams, $\mathrm{NLR}=$ negative likelihood ratio, $\mathrm{OR}=$ odds ratio, $\mathrm{PLR}=$ positive likelihood ratio, $\mathrm{SOAPP}=\mathrm{Screening}$ and Opioid Assessment for Patients with Pain.

\section{Discussion}

\section{Key Findings and Strength of Evidence}

The key findings of this review are summarized in the summary of evidence table (Table A) and the factors used to determine the overall SOE grades are summarized in Appendix $\mathrm{G}$ in the full report. For a number of Key Questions, we identified no studies meeting inclusion criteria. For Key Questions where studies were available, the SOE was rated no higher than low, due to small numbers of studies and methodological shortcomings, with the exception of buccal or intranasal fentanyl for pain relief outcomes within 2 hours after dosing, for which the SOE was rated moderate.

For effectiveness and comparative effectiveness, we identified no studies of long-term opioid therapy in patients with chronic pain versus no opioid therapy or nonopioid alternative therapies that evaluated outcomes at 1 year or longer. No studies examined how effectiveness varies based on various factors, including type of pain and patient characteristics. Most placebo-controlled randomized trials were shorter than 6 weeks in duration ${ }^{43}$ and no cohort studies on the effects of long-term opioid therapy versus no opioid therapy on outcomes related to pain, function, or quality of life were found. Although uncontrolled studies of patients prescribed opioids are available, ${ }^{8}$ findings are difficult to interpret due to the lack of a nonopioid comparison group.

Regarding harms, new evidence (published since the APS review) from observational studies suggests that being prescribed long-term opioids for chronic pain is associated with increased risk of abuse, ${ }^{44}$ overdose,,${ }^{45}$ fractures,,${ }^{18,46}$ and myocardial infarction, ${ }^{47}$ versus not currently being prescribed opioids. In addition, several recent studies 
suggest that the risk is dose-dependent, with higher opioid doses associated with increased risk. ${ }^{11,18,44,45,48,49}$ Although two studies found an association between opioid dose and increased risk of overdose starting at relatively low doses (20 to $49 \mathrm{mg} \mathrm{MED/day),} \mathrm{estimates} \mathrm{at} \mathrm{higher} \mathrm{doses} \mathrm{were}$ variable (adjusted HR 11.18 at $>100 \mathrm{mg} \mathrm{MED/day} \mathrm{versus}$ adjusted OR 2.88 for $>200 \mathrm{mg}$ MED/day). ${ }^{45,49}$ However, few studies evaluated each outcome and the population evaluated and duration of opioid therapy were not always well characterized. In addition, as in all observational studies, findings are susceptible to residual confounding despite use of statistical adjustment and other techniques such as matching. A study also found long-term opioid therapy associated with increased likelihood of receiving prescriptions for erectile dysfunction or testosterone, which may be markers for sexual dysfunction due to presumed endocrinological effects of opioids. ${ }^{11}$ However, it did not directly measure sexual dysfunction, and patients may seek or receive these medications for other reasons.

No study assessed the risk of abuse, addiction, or related outcomes associated with long-term opioid therapy use versus placebo or no opioid therapy. In uncontrolled studies, rates of abuse and related outcomes varied substantially, even after restricting inclusion to studies that evaluated patients on opioid therapy for at least one year and used pre-defined methods for ascertaining these outcomes, and stratifying studies according to whether they evaluated primary care populations or patients evaluated in pain clinic settings. ${ }^{50-60}$ An important reason for the variability in estimates is differences in patient samples and in how terms such as addiction, abuse, misuse, and dependence were defined in the studies, and in methods used to identify these outcomes (e.g., formal diagnostic interview with patients versus chart review or informal assessment). In one study, estimates of opioid misuse were lower based on independent review than based on assessments by the treating physician..$^{59}$ No study evaluated patients with "opioid use disorder" as recently defined in the new DSM-V. ${ }^{61}$

Evidence on the effectiveness of different opioid dosing strategies is also extremely limited. One new trial of a more liberal dose escalation strategy versus maintenance of current doses found no differences in outcomes related to pain, function, or risk of withdrawal from the study due to opioid misuse, but the difference in opioid doses between groups at the end of the trial was small (52 versus $40 \mathrm{mg}$ MED/day). ${ }^{62}$ One study from Washington State reported a decrease in the number of opioid-associated overdose deaths after implementing a dose threshold, ${ }^{63}$ but did not meet inclusion criteria for this review because it was an ecological, before-after study, and it is not possible to reliably determine whether changes in the number of opioid overdose deaths were related to other factors that could have impacted opioid prescribing practices.

Evidence on benefits and harms of different methods for initiating and titrating opioids, short- versus long-acting opioids, scheduled and continuous versus as-needed dosing of opioids, use of opioid rotation, and methods for titrating or discontinuing patients off opioids was not available or too limited to reach reliable conclusions.

We also found limited evidence on the comparative benefits and harms of specific opioids. Three head-to-head trials found few differences in pain relief between various longacting opioids at 1 year followup, ${ }^{64-66}$ but the usefulness of these studies for evaluating comparative effectiveness may be limited because patients in each arm had doses titrated to achieve adequate pain control. None of the trials was designed to evaluate abuse, addiction, or related outcomes.

Methadone has been an opioid of particular interest because it is disproportionately represented in case series and epidemiological studies of opioid-associated deaths. ${ }^{67}$ Characteristics of methadone that may be associated with increased risk of serious harms are its long and variable half-life, which could increase the risk for accidental overdose, and its association with electrocardiographic QTc interval prolongation, which could increase the risk of potentially life-threatening ventricular arrhythmia. ${ }^{68}$ However, the highest-quality observational study, which was conducted in VA patients with chronic pain and controlled well for confounders using a propensity-adjusted analysis, found methadone to be associated with lower risk of mortality as compared with sustained-release morphine. ${ }^{69}$ These results suggest that in some settings, methadone may not be associated with increased mortality risk, though research is needed to understand the factors that contribute to safer prescribing in different clinical settings.

Although five randomized trials found buccal or intranasal fentanyl more effective than placebo or oral opioids for treating acute exacerbations of chronic pain, all focused on short-term treatment and immediate outcomes in the minutes or hours after administration..$^{70-74}$ No study was designed to assess long-term benefits or harms, including accidental overdose, abuse, or addiction. In 2007, the U.S. FDA released a public health advisory due to case reports of deaths and other life-threatening adverse effects in patients prescribed buccal fentanyl. ${ }^{75}$

Evidence also remains limited on the utility of opioid risk assessment instruments, used prior to initiation of opioid therapy, for predicting likelihood of subsequent opioid abuse or misuse. In three studies of the ORT, estimates were extremely inconsistent (sensitivity ranged from 0.20 
to 0.99$).{ }^{76-78}$ A study that directly compared the accuracy of the ORT and two other risk assessment instruments reported weak likelihood ratios for predicting future abuse or misuse (PLR 1.27 to 1.65 and NLR 0.86 to 0.91 ). ${ }^{76}$ Risk prediction instruments other than the ORT (such as the SOAPP version 1, revised SOAPP, or DIRE) were only evaluated in one or two studies, and require further validation. Studies on the accuracy of risk instruments for identifying aberrant behavior in patients already prescribed opioids are available, ${ }^{53,56,76,79-85}$ but were outside the scope of this review.

No study evaluated the effectiveness of risk mitigation strategies, such as use of risk assessment instruments, opioid management plans, patient education, urine drug screening, prescription drug monitoring program data, monitoring instruments, more frequent monitoring intervals, pill counts, or abuse-deterrent formulations on outcomes related to overdose, addiction, abuse or misuse. Studies on effects of risk mitigation strategies were primarily focused on ability to detect misuse (e.g., urine drug testing and prescription monitoring program data) or on effects on markers of risky prescribing practices or medication-taking behaviors, ${ }^{86}$ and did not meet inclusion criteria for this review, which focused on effects on clinical outcomes. One study found that rates of poison center treatment incidents and opioid-related treatment admissions increased at a lower rate in States with a prescription drug monitoring program than in States without one, but used an ecological design, did not evaluate a cohort of patients prescribed opioids for chronic pain, and was not designed to account for other factors that could have impacted opioid prescribing practices. ${ }^{86}$

Although evidence indicates that patients with a history of substance abuse or at higher risk for abuse or misuse due to other risk factors are more likely to be prescribed opioids than patients without these risk factors, ${ }^{87-90}$ we identified no study on the effectiveness of methods for mitigating potential harms associated with long-term opioid therapy in high-risk patients.

\section{Findings in Relationship to What is Already Known}

Our findings are generally consistent with prior systematic reviews of opioid therapy for chronic pain that also found no long-term, placebo-controlled randomized trials. ${ }^{8,43}$ One systematic review of outcomes associated with long-term opioid therapy concluded that many patients discontinue treatment due to adverse events or insufficient pain relief, though patients who continue opioid therapy experience clinically significant pain relief. ${ }^{8}$ However, results of the studies included in this review are difficult to interpret because the studies had no nonopioid therapy control group, reported substantial between-study heterogeneity, and were susceptible to potential attrition and selection bias. Our findings are also consistent with a systematic review on comparative benefits and harms of various longacting opioids and short- versus long-acting opioids, which found no clear differences, primarily based on short-term randomized trials. ${ }^{91}$

Our review reported rates of abuse and related outcomes that are higher than a previously published systematic review of long-term opioid therapy that reported a very low rate of opioid addiction $(0.27$ percent $) .{ }^{8}$ Factors that may explain this discrepancy are that the prior review included studies that did not report predefined methods for ascertaining opioid addiction, potentially resulting in underreporting, and primarily included studies that excluded high-risk patients. Like a previous systematic review, we found variability in estimates of abuse and related outcomes, with some potential differences in estimates based on clinical setting (primary care versus pain clinic) and patient characteristics (e.g., exclusion of high-risk patients). ${ }^{92}$

Regarding risk mitigation strategies, our findings were similar to a previously published systematic review that found weak evidence with which to evaluate risk prediction instruments. ${ }^{93}$ Unlike our review, which found no evidence on effects of risk mitigation strategies on risk of abuse, addiction, or related outcomes, a previously published review found use of opioid management plans and urine drug screens to be associated with decreased risk of misuse behaviors. ${ }^{14}$ However, this conclusion was based on four studies that did not meet inclusion criteria for our review because effects of opioid management plans and urine drug screens could not be separated from other concurrent opioid prescribing interventions, ${ }^{94,95}$ use of a historical control group, ${ }^{96,97}$ or before-after study design. ${ }^{94}$

\section{Applicability}

A number of issues could impact the applicability of our findings. One challenge was difficulty in determining whether studies focused on patients with chronic pain. Although a number of large observational studies reported harms based on analyses of administrative databases, they were frequently limited in their ability to assess important clinical factors such as the duration or severity of pain. For some of these studies, we inferred the presence of chronic pain from prescribing data, such as the number of prescriptions over a defined period or the use of long-acting opioid preparations. Some potentially relevant studies were excluded because it was not possible to determine whether the sample evaluated had chronic pain or received longterm therapy. ${ }^{16,98-103}$ 
Another issue that could impact applicability is the type of opioid used in the studies. Both long-acting and short-acting opioids are often prescribed for chronic pain. In some studies, use of short-acting opioids predominated. ${ }^{11,18,49}$ Results of studies of short-acting opioids may not generalize to patients prescribed longacting opioids.

Selection of patients could also impact applicability. The few randomized trials that met inclusion criteria typically excluded patients at high risk of abuse or misuse and frequently used run-in periods prior to allocating treatments. The use of a run-in period preselects patients who respond to and tolerate initial exposure to the studied treatment. Therefore, benefits observed in the trials might be greater and harms lower than seen in actual clinical practice. ${ }^{104}$

Another factor impacting applicability is that most trials were not designed or powered to assess risk of abuse, addiction, or related outcomes. For example, trials of buccal fentanyl for acute exacerbations of chronic pain focused exclusively on immediate (episode-based) outcomes and were not designed to assess long-term outcomes, including outcomes related to the potential for abuse..$^{70-74}$ Long-term head-to-head trials of long-acting opioids excluded patients at high risk for these outcomes and reported no events. ${ }^{64-66}$

The setting in which studies were conducted could also impact applicability. As noted in other sections of this report, rates of overdose, abuse, addiction, and related outcomes are likely to vary based on the clinical setting. Therefore, we stratified studies reporting rates of abuse according to whether they were performed in primary care or pain clinic settings. The highest- quality comparative study of methadone versus another opioid (long-acting morphine) found decreased mortality risk but was conducted in a VA setting, ${ }^{69}$ which could limit applicability to other settings, due to factors such as how clinicians were trained in methadone use, policies on opioid prescribing, availability of resources to manage opioid prescribing, or other factors.

\section{Implications for Clinical and Policy Decisionmaking}

Our review has important implications for clinical and policy decisionmaking. Based on our review, most clinical and policy decisions regarding use of long-term opioid therapy must necessarily still be made on the basis of weak or insufficient evidence. This is in accordance with findings from a 2009 U.S. guideline on use of opioids for chronic pain, which found 21 of 25 recommendations supported by only low-quality evidence, ${ }^{105}$ and a 2010 Canadian guideline, ${ }^{106}$ which classified 3 of 24 recommendations as based on (short-term) randomized trials and 19 recommendations as based solely or partially on consensus opinion. Although randomized trials show short-term, moderate improvements in pain in highly selected, lowrisk populations with chronic pain, such efficacy-based evidence is of limited usefulness for informing long-term opioid prescribing decisions in clinical practice.

Given the marked increase in numbers of overdose deaths and other serious adverse events that have occurred following the marked increase in opioid prescribing for chronic pain, recent policy efforts have focused on safer prescribing of opioids. A recent review of opioid guidelines found broad agreement regarding a number of risk mitigation strategies despite weak evidence, such as riskassessment guided patient assessment for opioid therapy, urine drug testing, use of prescription monitoring program data, abuse-deterrent formulations, and opioid management plans. ${ }^{107}$ Based on low-quality evidence regarding harms associated with long-term opioid therapy, our review provides some limited support for clinical policy efforts aimed at reducing harms. One area in which there has been less agreement across guidelines is whether dose thresholds that warrant more intense monitoring or used to define maximum ceiling doses should be implemented, and if so, what is the appropriate threshold. Some evidence is now available on dose-dependent harms associated with opioids, ${ }^{45,49}$ which could help inform policies related to dose thresholds. However, research on the effects of implementing dose thresholds on clinical outcomes is limited to a single ecological study. ${ }^{63}$ In addition, although two observational studies were consistent in reporting a relationship between higher opioid dose and risk of overdose, estimates were highly variable at similar doses. ${ }^{45,49}$ This makes it difficult to determine an optimal maximum dose threshold based on an objective parameter, such as a dose inflection point where risk rises markedly. Other studies have begun to characterize cardiovascular, endocrinological, and injury-related harms associated with long-term opioid therapy and could be used to inform clinical decisions, though using such information in balanced assessments to inform clinical and policy decisionmaking remains a challenge given the lack of evidence regarding long-term benefits.

\section{Limitations of the Review Process}

We excluded non-English language articles and did not search for studies published only as abstracts. We did not attempt meta-analysis or assess for publication bias using graphical or statistical methods to detect small sample effects due to the paucity of evidence. Although we found no evidence of unpublished studies through searches on clinical trial registries and regulatory documents and 
solicitation of unpublished studies through SIP requests, the usefulness of such methods for identifying unpublished observational studies may be limited, as such studies are often not registered. We identified no unpublished randomized trials meeting inclusion criteria. We focused on studies that reported outcomes after at least one year of opioid therapy, though applying a shorter duration threshold for inclusion could have provided additional evidence. However, we identified no placebo-controlled trials of opioid therapy for at least 6 months.

\section{Limitations of the Evidence Base}

As noted previously, the critical limitation of our review is the lack of evidence in the target population (patients with chronic pain) and intervention (long-term opioid therapy), despite broadening of inclusion criteria to incorporate studies in which we assumed that patients were being treated for chronic pain due to the type of opioid prescribed (long-acting opioid) or number of prescriptions. We were also unable to determine how benefits and harms vary in subgroups, such as those defined by demographic characteristics, characteristics of the pain condition, and other patient characteristics (e.g., medical or psychological comorbidities). Due to the lack of evidence and methodological shortcomings in the available studies, no body of evidence (with the exception of buccal or intranasal fentanyl for immediate pain relief) was rated higher than low, meaning that conclusions are highly uncertain.

\section{Research Gaps}

Many research gaps limit the full understanding of the effectiveness, comparative effectiveness, and harms of long-term opioid therapy, as well as of the effectiveness of different dosing methods and risk mitigation strategies, and effectiveness in special populations. Longer- term studies of patients clearly with chronic pain comparing those who are prescribed long-term opioid therapy with those receiving other pharmacological and non-pharmacological therapies are needed. Studies that include higher-risk patients, commonly treated with opioids in clinical practice, and that measure multiple important outcomes, including pain, physical and psychological functioning, as well as misuse and abuse, would be more helpful than efficacy studies focused solely on pain intensity. Greater standardization of methods for defining and identifying abuse-related outcomes in studies that report these outcomes are needed. The Initiative on Methods, Measurement, and Pain Assessment in Clinical Trials (IMMPACT) group recently issued recommendations on measuring abuse liability in analgesic clinical trials. ${ }^{108}$
Additional research is also needed to develop and validate risk prediction instruments, and to determine how using them impacts treatment decisions and, ultimately, patient outcomes. More research is needed on the comparative benefits and harms of different opioids or formulations and different prescribing methods. Studies comparing effectiveness and harms of methadone versus other longacting opioids, to determine if findings from a study ${ }^{69}$ conducted in a VA setting are reproducible in other settings, and to better understand factors associated with safer methadone prescribing.

Research is also needed to understand the effects of risk mitigation strategies such as urine drug screening, use of prescription drug monitoring program data, and abusedeterrent formulations on clinical outcomes such as rates of overdose, abuse, addiction, and misuse. In one before-after study, the introduction of an abuse-deterrent opioid was followed by patients switching to other prescription opioids or illicit opioids, ${ }^{109}$ underscoring the need for research to understand both the positive and negative clinical effects of risk mitigation strategies.

Long-term randomized trials of opioid therapy are difficult to implement due to attrition, challenges in recruitment, or ethical factors (e.g., long-term allocation of patients with pain to placebo or allocation to non-use of risk mitigation strategies recommended in clinical practice guidelines). Nonetheless, pragmatic and other non-traditional randomized trial approaches could be used to address these challenges. ${ }^{110}$ Observational studies could also help address a number of these research questions, but should be specifically designed to evaluate patients with chronic pain prescribed long-term opioid therapy and appropriately measure and address potential confounders. Well-designed clinical registries that enroll patients with chronic pain prescribed and not prescribed chronic opioids could help address the limitations of studies based solely or primarily on administrative databases, which are often unable to fully characterize the pain condition (e.g., duration, type, and severity) or other clinical characteristics and frequently do not have information regarding outcomes related to pain, function, and quality of life. Such registry studies could be designed to extend the observations from randomized trials of opioids versus placebo or other treatments, but would differ from currently available studies by following patients who discontinue or do not start opioids, in addition to those who continue on or start opioid therapy. 


\section{Conclusions}

Evidence on long-term opioid therapy for chronic pain is very limited, but suggests an increased risk of serious harms that appears to be dose-dependent. Based on our review, most clinical and policy decisions regarding use of long-term opioid therapy must necessarily still be made on the basis of weak or insufficient evidence. More research is needed to understand long- term benefits, risk of abuse and related outcomes, and effectiveness of different opioid prescribing methods and risk mitigation strategies.

\section{References}

1. International Association for the Study of Pain. Classification of chronic pain: Descriptions of chronic pain syndromes and definitions of pain terms. Pain. 1986;3: S1-226. PMID: 3461421.

2. Institute of Medicine (U.S.) Committee on Advancing Pain Research Care and Education. Relieving Pain in America: A Blueprint for Transforming Prevention, Care, Education, and Research. Washington, DC: National Academies Press; 2011.

3. Ballantyne JC, Shin NS. Efficacy of opioids for chronic pain: A review of the evidence. Clinical J Pain. 2008;24(6):469-478. PMID: 18574357.

4. Eriksen J, Sjogren P, Bruera E, Ekholm O, Rasmussen NK. Critical issues on opioids in chronic non-cancer pain: an epidemiological study. Pain. 2006;125(1-2):172-179. PMID: 16842922.

5. Sullivan MD, Edlund MJ, Fan M-Y, DeVries A, Brennan Braden J, Martin BC. Trends in use of opioids for noncancer pain conditions 2000-2005 in Commercial and Medicaid insurance plans: The TROUP study. Pain. 2008;138(2):440-449. PMID: 18547726.

6. Boudreau D, Von Korff M, Rutter CM, et al. Trends in long-term opioid therapy for chronic non-cancer pain. Pharmacoepidemiol Drug Saf. 2009;18(12):1166-1175. PMID: 19718704.

7. Olsen Y, Daumit GL, Ford DE. Opioid prescriptions by U.S. primary care physicians from 1992 to 2001. J Pain. 2006;7(4):225-235. PMID: 16618466.

8. Noble M, Treadwell JR, Tregear SJ, et al. Long-term opioid management for chronic noncancer pain. Cochrane Database Syst Rev. 2010(11):CD006605. doi: 10.1002/14651858.CD006605.pub2. PMID: 20091598.

9. Chou R, Fanciullo GJ, Fine PG, et al. Clinical guidelines for the use of chronic opioid therapy in chronic noncancer pain. J Pain. 2009;10(2):113-130. PMID: 19187889.

10. Starrels JL, Becker WC, Weiner MG, Li X, Heo M, Turner BJ. Low use of opioid risk reduction strategies in primary care even for high-risk patients with chronic pain. J Gen Intern Med. 2011;26(9):958-964. PMID: 21347877.
11. Deyo RA, Smith DH, Johnson ES, et al. Prescription opioids for back pain and use of medications for erectile dysfunction. Spine. 2013;38(11):909-915. PMID: 23459134.

12. Substance Abuse and Mental Health Services Administration. Treatment Episode Data Set (TEDS). 1999 - 2009. National Admissions to Substance Abuse Treatment Services, DASIS Series: S-56. Rockville, MD: Substance Abuse and Mental Health Services Administration; 2011.

13. Substance Abuse and Mental Health Services Administration. The DAWN Report: Highlights of the 2010 Drug Abuse Warning Network (DAWN) Findings on Drug-Related Emergency Department Visits. Rockville, MD: Center for Behavioral Health Statistics and Quality; 2012.

14. Starrels JL, Becker WC, Alford DP, Kapoor A, Williams A, Turner BJ. Systematic review: treatment agreements and urine drug testing to reduce opioid misuse in patients with chronic pain. Ann Intern Med. 2010;152:712-720. PMID: 20513829.

15. Warner M, Chen LH, Makuc DM, Anderson RN, Minino AM. Drug poisoning deaths in the United States, 19802008. NCHS Data Brief. 2011;81:1-8. PMID: 22617462.

16. Bohnert ASB, Valenstein M, Bair MJ, et al. Association between opioid prescribing patterns and opioid overdoserelated deaths. JAMA. 2011;305(13):1315-1321. PMID: 21467284.

17. Volkow ND, McLellan TA. Curtailing diversion and abuse of opioid analgesics without jeopardizing pain treatment. JAMA. 2011;305(13):1346-1347. PMID: 21467287.

18. Saunders KW, Dunn KM, Merrill JO, et al. Relationship of opioid use and dosage levels to fractures in older chronic pain patients. J Gen Intern Med. 2010;25(4):310-315. PMID: 20049546.

19. Rolita L, Spegman A, Tang X, Cronstein BN. Greater number of narcotic analgesic prescriptions for osteoarthritis is associated with falls and fractures in elderly adults. J Am Geriatr Soc. 2013;61(3):335-340. PMID: 23452054.

20. Gomes T, Redelmeier DA, Juurlink DN, Dhalla IA, Camacho X, Mamdani MM. Opioid dose and risk of road trauma in Canada: a population-based study. JAMA Intern Med. 2013;173(3):196-201. PMID: 23318919.

21. Centers for Disease Control and Prevention. Prescription Drug Overdose in the United States: Fact Sheet. 2014. http://www.cdc.gov/homeandrecreational safety/overdose/ facts.html. Accessed July 17, 2014.

22. Furlan AD, Sandoval JA, Mailis-Gagnon A, Tunks E. Opioids for chronic noncancer pain: a meta-analysis of effectiveness and side effects. CMAJ. 2006;174(11): 1589-1594. PMID: 16717269. 
23. Daniell HW. Hypogonadism in men consuming sustainedaction oral opioids. J Pain. 2002;3:377-384.

PMID: 14622741.

24. Daniell HW. Opioid endocrinopathy in women consuming prescribed sustained-action opioids for control of nonmalignant pain. J Pain. 2008;9:28-36. PMID: 14622741.

25. Angst MS, Clark JD. Opioid-induced hyperalgesia: a qualitative systematic review. Anesthesiology. 2006;104(3):570-587. PMID: 16508405.

26. Chou R, Ballantyne JC, Fanciullo GJ, Fine PG, Miaskowski C. Research gaps on use of opioids for chronic noncancer pain: findings from a review of the evidence for an American Pain Society and American Academy of Pain Medicine clinical practice guideline. J Pain. 2009;10(2):147-159. PMID: 19187891.

27. Furlan AD, Reardon R, Weppler C, National Opioid Use Guideline Group (NOUGG). Opioids for chronic noncancer pain: a new Canadian practice guideline. CMAJ. 2011;182(9):923-930. PMID: 20439443.

28. United States Department of Veterans Affairs, The Management of Opioid Therapy for Chronic Pain Working Group. VA/DoD Clinical Practice Guideline for Management of Opioid Therapy for Chronic Pain' 2010. http://www.healthquality.va.gov/Chronic_Opioid_ Therapy_COT.asp. Accessed September 19, 2014.

29. American Pain Society-American Academy of Pain Medicine Opioids Guidelines Panel. Guideline for the Use of Chronic Opioid Therapy in Chronic Noncancer Pain: Evidence Review. http://www.americanpainsociety.org/ uploads/pdfs/Opioid_Final_Evidence_Report.pdf 2009. Accessed on September 19, 2014.

30. Owens D, Lohr KN, Atkins D, et al. Methods Guide for Effectiveness and Comparative Effectiveness Reviews. Rockville, MD: Agency for Healthcare Research and Quality. 2011.

31. Chou R. The effectiveness and risks of long-term opioid treatment of chronic pain. PROSPERO 2014:CRD42014007016; 2013. http://www.crd.york.ac.uk/ PROSPERO/display_record.asp?ID=CRD42014007016. Accessed September 19, 2014.

32. U.S. Food and Drug Administration. Extended-Release and Long-Acting (ER/LA) Opioid Analgesics Risk Evaluation and Mitigation Strategy (REMS) a single shared system - Current Application Holders. http://www.fda.gov/ downloads/Drugs/DrugSafety/InformationbyDrugClass/ UCM348818.pdf. Accessed September 19, 2014

33. Hall AJ, Logan JE, Toblin RL, et al. Patterns of abuse among unintentional pharmaceutical overdose fatalities. JAMA. 2008;300(22):2613-2620. PMID: 19066381.

34. Altman DG, Bland JM. Diagnostic tests 3: receiver operating characteristic plots. BMJ. 1994;309(6948):188. PMID: 8044101.
35. Zweig MH, Campbell G. Receiver-operating characteristic (ROC) plots: a fundamental evaluation tool in clinical medicine. Clin Chem. 1993;39(4):561-577.

PMID: 8472349.

36. Furlan AD, Pennick V, Bombardier C, van Tulder M. 2009 updated methods guidelines for systematic reviews in the Cochrane Back Review Group. Spine. 2009;24:1929-1941. PMID: 19680101.

37. U.S. Preventive Services Task Force. U.S. Preventive Services Task Force Procedure Manual. AHRQ Publication No. 08-05118-EF, July 2008. http://www. uspreventiveservicestaskforce.org/uspstf08/methods/ procmanual.htm. 2008. Accessed September 19, 2014.

38. Agency for Healthcare Research and Quality. Methods Guide for Medical Test Reviews. Agency for Healthcare Research and Quality: Rockville, MD; 2010. http:// effectivehealthcare.ahrq.gov/index.cfm/search-for-guidesreviews-and-reports/?pageaction=displayproduct\&product $\mathrm{id}=558$ Accessed September 19, 2014.

39. Whiting PF, Rutjes AWS, Westwood ME, et al. QUADAS-2: A revised tool for the Quality Assessment of Diagnostic Accuracy Studies. Ann Intern Med. 2011;155(8):529- 536. PMID: 22007046.

40. McGinn TG, Guyatt GH, Wyer PC, et al. Users' guides to the medical literature: XXII: how to use articles about clinical decision rules. JAMA. 2000;284(1):79-84. PMID: 10872017.

41. Agency for Healthcare Research and Quality. Methods guide for Effectiveness and Comparative Effectiveness Reviews. AHRQ Publication No. 10(13)-EHC063-EF. Rockville, MD: Agency for Healthcare Research and Quality. November 2013. Chapters available at: www. effectivehealthcare.ahrq.gov. Accessed September 19, 2014.

42. Atkins D, Chang SM, Gartlehner G, et al. Assessing applicability when comparing medical interventions: AHRQ and the Effective Health Care Program. J Clin Epidemiol. 2011;64(11):1198-1207. PMID: 21463926.

43. Furlan A, Chaparro LE, Irvin E, Mailis-Gagnon A. A comparison between enriched and nonenriched enrollment randomized withdrawal trials of opioids for chronic noncancer pain. Pain Res Manag. 2011;16(5): 337-351. PMID: 22059206.

44. Edlund MJ, Martin BC, Russo JE, Devries A, Braden JB, Sullivan M, D. The role of opioid prescription in incident opioid abuse and dependence among individuals with chronic noncancer pain. Clin J Pain. 2014;30(7):557-564. PMID: 24281273.

45. Dunn KM, Saunders KW, Rutter CM, et al. Opioid prescriptions for chronic pain and overdose: a cohort study. Ann Intern Med. 2010;152(2):85-92. PMID: 20083827. 
46. Li L, Setoguchi S, Cabral H, Jick S. Opioid use for noncancer pain and risk of fracture in adults: a nested casecontrol study using the general practice research database. Am J Epidemiol. 2013;178(4):559-569. PMID: 23639937.

47. Li L, Setoguchi S, Cabral H, Jick S. Opioid use for noncancer pain and risk of myocardial infarction amongst adults. J Intern Med. 2013;273(5):511-526.

PMID: 23331508.

48. Carman WJ, Su S, Cook SF, Wurzelmann JI, McAfee A. Coronary heart disease outcomes among chronic opioid and cyclooxygenase-2 users compared with a general population cohort. Pharmacoepidemiol Drug Saf. 2011;20(7):754-762. PMID: 21567652.

49. Gomes T, Mamdani MM, Dhalla IA, Paterson JM, Juurlink DN. Opioid dose and drug-related mortality in patients with nonmalignant pain. Arch Intern Med. 2011;171(7):686-691. PMID: 21482846.

50. Martell BA, O’Connor PG, Kerns RD, et al. Systematic review: opioid treatment for chronic back pain: prevalence, efficacy, and association with addiction. Ann Intern Med. 2007;146(2):116-127. PMID: 17227935.

51. Banta-Green CJ, Merrill JO, Doyle SR, Boudreau DM, Calsyn DA. Opioid use behaviors, mental health and pain-development of a typology of chronic pain patients. Drug Alcohol Depend. 2009;104(1- 2):34-42. PMID: 19473786.

52. Boscarino JA, Rukstalis M, Hoffman SN, et al. Risk factors for drug dependence among out-patients on opioid therapy in a large U.S. health-care system. Addiction. 2010;105(10):1776-1782. PMID: 20712819.

53. Compton PA, Wu SM, Schieffer B, Pham Q, Naliboff BD. Introduction of a self-report version of the Prescription Drug Use Questionnaire and relationship to medication agreement noncompliance. J Pain Symptom Manag. 2008;36(4):383-395. PMID: 18508231.

54. Cowan DT, Wilson-Barnett J, Griffiths P, Allan LG. A survey of chronic noncancer pain patients prescribed opioid analgesics. Pain Medicine. 2003;4(4):340-351. PMID: 14750910.

55. Fleming MF, Balousek SL, Klessig CL, Mundt MP, Brown DD. Substance use disorders in a primary care sample receiving daily opioid therapy. J Pain. 2007;8(7):573-582. PMID: 17499555.

56. Hojsted J, Nielsen PR, Guldstrand SK, Frich L, Sjogren P. Classification and identification of opioid addiction in chronic pain patients. Eur J Pain. 2010;14(10):1014-1020. PMID: 20494598.

57. Portenoy RK, Farrar JT, Backonja MM, et al. Longterm use of controlled-release oxycodone for noncancer pain: results of a 3-year registry study. Clin J Pain. 2007;23(4):287-299. PMID: 17449988.

58. Saffier K, Colombo C, Brown D, Mundt MP, Fleming MF. Addiction Severity Index in a chronic pain sample receiving opioid therapy. J Subst Abuse Treat. 2007;33(3):303-311. PMID: 17376639.
59. Schneider JP, Kirsh KL. Defining clinical issues around tolerance, hyperalgesia, and addiction: a quantitative and qualitative outcome study of long-term opioid dosing in a chronic pain practice. J Opioid Manag. 2010;6(6):385-395. PMID: 21268999.

60. Wasan AD, Butler SF, Budman SH, et al. Does report of craving opioid medication predict aberrant drug behavior among chronic pain patients? Clin J Pain. 2009;25(3): 193-198. PMID: 19333168.

61. American Psychiatric Association. Diagnostic and statistical manual of mental disorders, Fifth Edition. Arlington, VA: Amerian Psychiatric Association; 2013.

62. Naliboff BD, Wu SM, Schieffer B, et al. A randomized trial of 2 prescription strategies for opioid treatment of chronic nonmalignant pain. J Pain. 2011;12(2):288-296. PMID: 21111684.

63. Franklin GM, Mai J, Turner J, Sullivan M, Wickizer T, Fulton-Kehoe D. Bending the prescription opioid dosing and mortality curves: impact of the Washington State opioid dosing guideline. Am J Ind Med. 2012;55(4): 325-331. PMID: 22213274.

64. Allan L, Richarz U, Simpson K, Slappendel R. Transdermal fentanyl versus sustained release oral morphine in strong-opioid naive patients with chronic low back pain. Spine (Phila Pa 1976). 2005;30(22):2484-2490. PMID: 16284584.

65. Mitra F, Chowdhury S, Shelley M, Williams G. A feasibility study of transdermal buprenorphine versus transdermal fentanyl in the long-term management of persistent non-cancer pain. Pain Med. 2013;14(1):75-83. PMID: 23320402.

66. Wild JE, Grond S, Kuperwasser B, et al. Long-term safety and tolerability of tapentadol extended release for the management of chronic low back pain or osteoarthritis pain. Pain Pract. 2010;10(5):416-427. PMID: 20602712.

67. Chou R, Cruciani RA, Fiellin DA, et al. Methadone safety: a clinical practice guideline from the American Pain Society and College on Problems of Drug Dependence, in collaboration with the Heart Rhythm Society. J Pain. 2014;15(4):321-337. PMID: 24685458.

68. Chou R, Weimer MB, Dana T. Methadone overdose and cardiac arrhythmia potential: findings from a review of the evidence for an American Pain Society and College on Problems of Drug Dependence clinical practice guideline. J Pain. 2014;15(4):338-365. PMID: 24685459.

69. Krebs EE, Becker WC, Zerzan J, Bair MJ, McCoy K, Hui S. Comparative mortality among Department of Veterans Affairs patients prescribed methadone or long-acting morphine for chronic pain. Pain. Aug;152(8):1789-1795. PMID: 21524850. 
70. Ashburn MA, Slevin KA, Messina J, Xie F. The efficacy and safety of fentanyl buccal tablet compared with immediate-release oxycodone for the management of breakthrough pain in opioid-tolerant patients with chronic pain. Anesth Analg. 2011;112(3):693-702.

PMID: 21304148.

71. Davies A, Sitte T, Elsner F, et al. Consistency of efficacy, patient acceptability, and nasal tolerability of fentanyl pectin nasal spray compared with immediate-release morphine sulfate in breakthrough cancer pain. J Pain Symptom Manag. 2011;41(2):358-366. PMID: 21334555.

72. Portenoy RK, Messina J, Xie F, Peppin J. Fentanyl buccal tablet (FBT) for relief of breakthrough pain in opioid-treated patients with chronic low back pain: a randomized, placebo-controlled study. Curr Med Res Opin. 2007;23(1):223-233. PMID: 17207304.

73. Simpson DM, Messina J, Xie F, Hale M. Fentanyl buccal tablet for the relief of breakthrough pain in opioid-tolerant adult patients with chronic neuropathic pain: a multicenter, randomized, double-blind, placebo-controlled study. Clin Ther. 2007;29(4):588-601. PMID: 17617282.

74. Webster LR, Slevin KA, Narayana A, Earl CQ, Yang R. Fentanyl buccal tablet compared with immediate-release oxycodone for the management of breakthrough pain in opioid-tolerant patients with chronic cancer and noncancer pain: a randomized, double-blind, crossover study followed by a 12 -week open-label phase to evaluate patient outcomes. Pain Med. 2013;14(9):1332-1345. PMID: 23855816.

75. U.S. Food and Drug Administration. Public Health Advisory: Important Information for the Safe Use of Fentora (fentanyl buccal tablets). 2013. Available at:http://www.fda.gov/Drugs/DrugSafety/ PostmarketDrugSafetyInformationforPatientsandProviders/ DrugSafetyInformationforHeathcareProfessionals/ PublicHealthAdvisories/ucm051273.htm. Accessed on May 22, 2014.

76. Jones T, Moore T. Preliminary data on a new opioid risk assessment measure: the Brief Risk Interview. J Opioid Manag. 2013;9(1):19-27. PMID: 23709300.

77. Moore TM, Jones T, Browder JH, Daffron S, Passik SD. A comparison of common screening methods for predicting aberrant drug-related behavior among patients receiving opioids for chronic pain management. Pain Med. 2009;10(8):1426-1433. PMID: 20021601.

78. Webster LR, Webster RM. Predicting aberrant behaviors in opioid-treated patients: preliminary validation of the Opioid Risk Tool. Pain Med. 2005;6(6):432-442. PMID: 16336480.

79. Butler SF, Budman SH, Fanciullo GJ, Jamison RN. Cross validation of the current opioid misuse measure to monitor chronic pain patients on opioid therapy. Clin J Pain. 2010;26(9):770-776. PMID: 20842012.
80. Butler SF, Budman SH, Fernandez KC, Fanciullo GJ, Jamison RN. Cross-validation of a screener to predict opioid misuse in chronic pain patients (SOAPP-R). J Addict Med. 2009;3(2):66-73. PMID: 20161199.

81. Fleming MF, Davis J, Passik SD. Reported lifetime aberrant drug-taking behaviors are predictive of current substance use and mental health problems in primary care patients. Pain Med. 2008;9(8):1098-1106. PMID: 18721174.

82. Meltzer EC, Rybin D, Saitz R, et al. Identifying prescription opioid use disorder in primary care: diagnostic characteristics of the Current Opioid Misuse Measure (COMM). Pain. 2011;152(2):397-402. PMID: 21177035.

83. Butler SF, Budman SH, Fernandez KC, et al. Development and validation of the Current Opioid Misuse Measure. Pain. 2007;130(1-2):144-156. PMID: 17493754.

84. Holmes CP, Gatchel RJ, Adams LL, et al. An opioid screening instrument: long-term evaluation of the utility of the Pain Medication Questionnaire. Pain Pract. 2006;6(2):74-88. PMID: 17309714.

85. Butler SF, Fernandez K, Benoit C, Budman SH, Jamison RN. Validation of the revised Screener and Opioid Assessment for Patients with Pain (SOAPP-R). J Pain. 2008;9(4):360-372. PMID: 18203666.

86. Reifler LM, Droz D, Bailey JE, et al. Do prescription monitoring programsi mpact State trends in opioid abuse/ misuse? Pain Med. 2012;13(3):434-442. PMID: 22299725.

87. Deyo RA, Smith DH, Johnson ES, et al. Opioids for back pain patients: primary care prescribing patterns and use of services. J Am Board Fam Med. 2011;24(6):717-727. PMID: 22086815.

88. Seal KH, Shi Y, Cohen G, et al. Association of mental health disorders with prescription opioids and high-risk opioid use in U.S. veterans of Iraq and Afghanistan. JAMA. 2012;307(9):940-947. PMID: 22396516.

89. Sullivan MD, Edlund MJ, Zhang L, Unutzer J, Wells KB. Association between mental health disorders, problem drug use, and regular prescription opioid use. Arch Intern Med. 2006;166(19):2087-2093. PMID: 17060538.

90. Morasco BJ, Duckart JP, Carr TP, Deyo RA, Dobscha SK. Clinical characteristics of veterans prescribed high doses of opioid medications for chronic non-cancer pain. Pain. 2010;151(3):625-632. PMID: 20801580.

91. Carson S, Thakurta S, Low A, Smith B, Chou R. Drug Class Review: Long-Acting Opioid Analgesics: Final Update 6 Report. Portland, OR: Oregon Health \& Science University; 2011. PMID: 21977550.

92. Fishbain DA, Cole B, Lewis J, Rosomoff HL, Rosomoff RS. What percentage of chronic nonmalignant pain patients exposed to chronic opioid analgesic therapy develop abuse/addiction and/or aberrant drug-related behaviors? A structured evidence-based review. Pain Med. 2008;9(4):444-459. PMID: 18489635. 
93. Turk DC, Swanson KS, Gatchel RJ. Predicting opioid misuse by chronic pain patients: a systematic review and literature synthesis. Clin J Pain. 2008;24(6):497-508. PMID: 18574359.

94. Wiedemer NL, Harden PS, Arndt IO, Gallagher RM. The opioid renewal clinic: a primary care, managed approach to opioid therapy in chronic pain patients at risk for substance abuse. Pain Med. 2007;8(7):573-584. PMID: 17883742.

95. Goldberg KC, Simel DL, Oddone EZ. Effect of an opioid management system on opioid prescribing and unscheduled visits in a large primary care clinic. JCOM. 2005;12(12):621-628.

96. Manchikanti L, Manchukonda R, Damron KS, Brandon D, McManus CD, Cash K.Does adherence monitoring reduce controlled substance abuse in chronic pain patients? Pain Physician. 2006;9(1):57-60. PMID: 16700282.

97. Manchikanti L, Manchukonda R, Pampati V, et al. Does random urine drug testing reduce illicit drug use in chronic pain patients receiving opioids? Pain Physician. 2006;9(2):123-129. PMID: 16703972.

98. Paulozzi LJ, Kilbourne EM, Shah NG, et al. A history of being prescribed controlled substances and risk of drug overdose death. Pain Med. 2012;13(1):87-95. PMID: 22026451.

99. Byas-Smith MG, Chapman SL, Reed B, Cotsonis G. The effect of opioids on driving and psychomotor performance in patients with chronic pain. Clin J Pain. 2005;21(4):3 45-352. PMID: 15951653.

100. Gaertner J, Frank M, Bosse B, et al. [Oral controlledrelease oxycodone for the treatment of chronic pain. Data from 4196 patients]. Schmerz. 2006;20(1):61-68. PMID: 15926076.

101. Galski T, Williams JB, Ehle HT. Effects of opioids on driving ability. J Pain Symptom Manage. 2000;19(3): 200-208. PMID: 10760625.

102. Sabatowski R, Schwalen S, Rettig K, Herberg KW, Kasper SM, Radbruch L. Driving ability under long-term treatment with transdermal fentanyl. J Pain Symptom Manage. 2003;25(1):38-47. PMID: 12565187.

103. Menefee LA, Frank ED, Crerand C, et al. The effects of transdermal fentanyl on driving, cognitive performance, and balance in patients with chronic nonmalignant pain conditions. Pain Med. 2004;5(1):42-49. PMID: 14996236.
104. Pablos-Mendez A, Barr RG, Shea S. Run-in periods in randomized trials: implications for hte application of results in clinical practice. JAMA. 1998;279(3):222-225. PMID: 9438743.

105. Chou R, Fanciullo GJ, Fine PG, Miaskowski C, Passik $\mathrm{SD}$, Portenoy RK. Opioids for chronic noncancer pain: prediction and identification of aberrant drug-related behaviors: a review of the evidence for an American Pain Society and American Academy of Pain Medicine clinical practice guideline. J Pain. 2009;10(2):131-146. PMID: 19187890.

106. Furlan AD, Reardon R, Weppler C. Opioids for chronic noncancer pain: a new Canadian practice guideline. CMAJ. 2010;182(9):923- 930. PMID: 20439443.

107. Nuckols TK, Anderson L, Popescu I, et al. Opioid prescribing: a systematic review and critical appraisal of guidelines for chronic pain. Annals Intern Med. 2014;160(1):38- 47. PMID: 24217469.

108. O’Connor AB, Turk DC, Dworkin RH, et al. Abuse liability measures for use in analgesic clinical trials in patients with pain: IMMPACT Recommendations. Pain. 2013;154(11):2324-2334. PMID: 24148704.

109. Cicero TJ, Ellis MS, Surratt HL. Effect of abusedeterrent formulation of OxyContin. N Engl J Med. 2012;367(2):187-189. PMID: 22784140.

110. Roland M, Torgerson DJ. Understanding controlled trials: What are pragmatic trials? BMJ. 1998;316:285. PMID: 947251.

\section{Full Report}

This executive summary is part of the following document: Chou R, Deyo R, Devine B, Hansen R, Sullivan S, Jarvik JG, Blazina I, Dana T, Bougatsos C, Turner J. The Effectiveness and Risks of Long-Term Opioid Treatment of Chronic Pain. Evidence Report/Technology Assessment No. 218. (Prepared by the Pacific Northwest Evidencebased Practice Center under Contract No. 290-2012-00014I.) AHRQ Publication No. 14-E005-EF. Rockville, MD: Agency for Healthcare Research and Quality; September 2014. www.effectivehealthcare.ahrq.gov/reports/final.cfm. DOI: https://doi.org/10.23970/AHRQEPCERTA218. 